Technical Memorandum 33-510

\title{
Solar Electric Propulsion System Technology
}

\author{
T. D. Masek \\ T. W. Macie
}
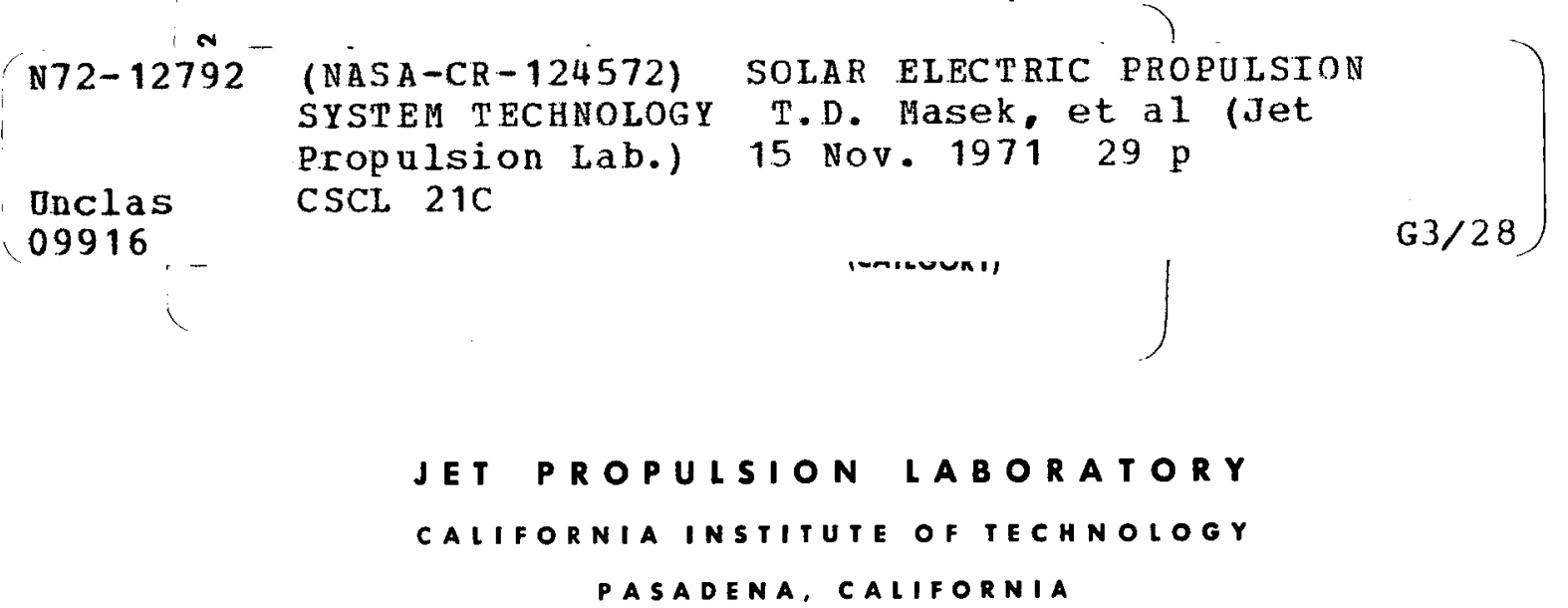
NATIONAL AERONAUTICS AND SPACE ADMINISTRATION

\title{
Technical Memorandum 33-510
}

\section{Solar Electric Propulsion System Technology}

\author{
T. D. Masek \\ T. W. Macie
}

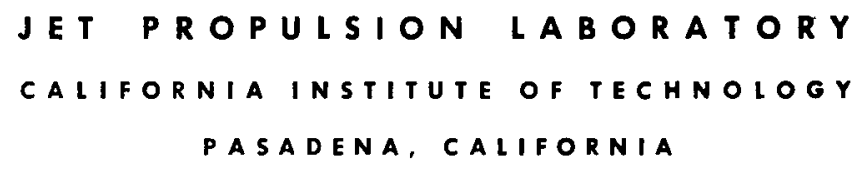

November 15,1971 
Prepared Under Contract No. NAS 7-100 National Aeronautics and Space Administration 


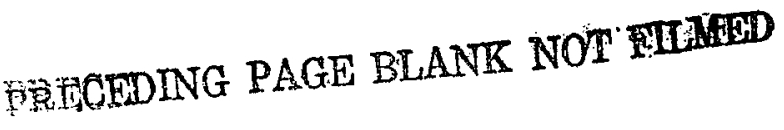

\author{
PREFACE
}

The work described in this report was performed by the Propulsion Division of the Jet Propulsion Laboratory. 
I. Introduction ....................... 1

II. Basic Characteristics of the SEP System ............

III. SEP Element Development Status ............... 2

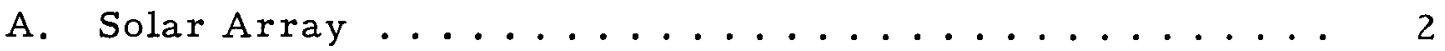

B. Maximum Power Point Detector .............. 4

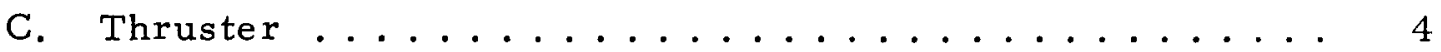

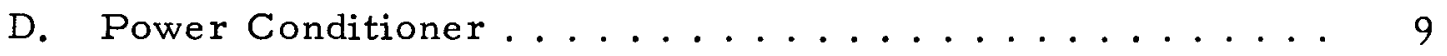

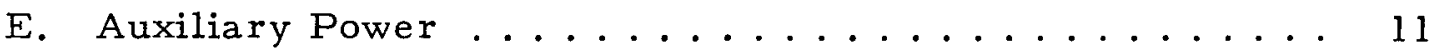

F. Switching Matrix ................... 11

G. Propellant Storage .................... 12

H. Thrust Vector Control-Mechanism ............ 12

I. Thrust Vector Control-Electronics ........... 16

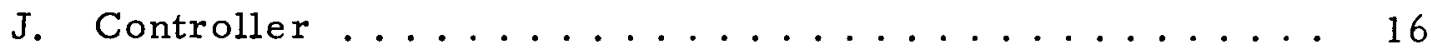

IV. SEP System - Spacecraft Interactions . . . . . . . . . 17

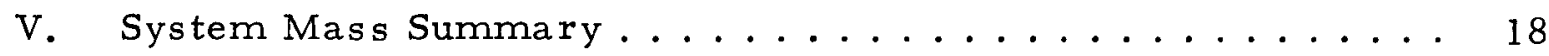

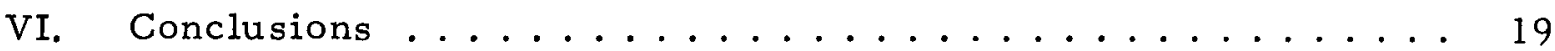

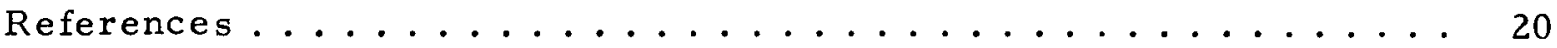

TAB LES

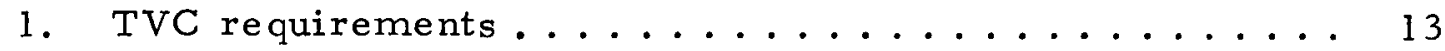

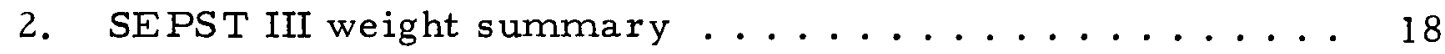
FIGURES

1. Propulsion system block diagram ............ 2

2. General Electric roll-out solar array ........... 3

3. Solar array current vs voltage characteristic

(typical).......................... 4 


\section{CONTENTS (contd)}

\section{FIGURES (contd)}

4. Solar array impedance as a function of

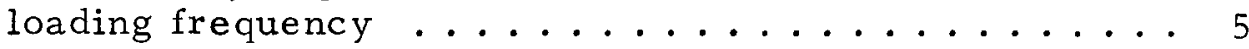

5. JPL $20-\mathrm{cm}$ diameter thruster ............ 6

6. Thruster power efficiency and total efficiency as a function of specific impulse............ 9

7. Thruster throttling characteristics ..........

8. Hughes Aircraft Co. power conditioner ........ 10

9. Mercury propellant tank components ......... 12

10. JPL thrust vector control mechanism ......... 13

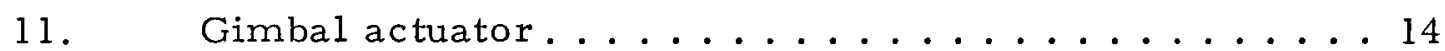

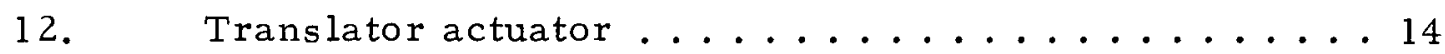

13. Basic translator axis or gimbal axis control

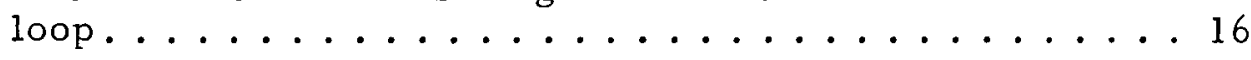

14. Translator control loop phase plane response ..... 17

15. Total propulsion system specific mass as a function of power into the power conditioners ..... 19 


\begin{abstract}
As the number of possible applications for primary solar powered electric propulsion grows, the burden of demonstrating this technology grows in proportion. The solar electric propulsion system technology (SEPST)program at JPL is focusing on such a demonstration. This paper reports the progress of the present JPL hardware program (SEPST III) and discusses certain propulsion system-spacecraft interaction problems being investigated.

The basic solar electric propulsion system concept and elements are reviewed. Hardware is discussed only briefly, relying on detailed fabrication or assembly descriptions reported elsewhere. Emphasis is placed on recent performance data, which are presented to show the relationship between spacecraft requirements and present technology.
\end{abstract}




\section{Introduction}

Solar electric propulsion (SEP) system technology has reached a critical state of development. All system elements known to be required for typical spacecraft concepts are presently approaching an advanced state. However, in most cases before these element designs can be converted into flight articles, specific spacecraft requirements are needed to fix power level or size. Little will be gained from further system development if this development entails only repackaging or environmental testing. The definition of a mission and the associated spacecraft will become the pacing item in SEP development by mid-1971.

Substantial effort is presently being expended toward mission definition for a solar electric spacecraft, with the most thoroughly studied SEP mission being an asteroid belt probe. (1-4) Other current mission candidates include out-of-the-ecliptic and solar probes, comet and asteroid rendezvous, and major planet orbiters. Typically, these candidate missions can be performed with power levels in the range of 10 to $20 \mathrm{~kW}$ depending upon the launch vehicle selected. Multimission capability $(1,2,5)$ will require the selection of a specific power level to accomplish all or a series of these missions. This selection can occur only after completion of detailed mission and spacecraft studies.

However, the relatively wide range of power levels open for selection places two constraints on the current SEP system development, which must a priori focus on a given power level and specific impulse. First, since the system development is costly and time consuming, the technology developed must apply continuously throughout the power range. Principally this power range requires a working knowledge of thruste $r$ and power conditioner operation and efficiency dependence on powe $r$ level and specific impulse. Extrapolations made from the hardware design point can then be supported by analysis. Second, reasonably good weight estimates must be established to refine mission calculations. Present calculations include $30 \mathrm{~kg} / \mathrm{kW}$ for the total propulsion system including the solar array. Since trajectory calculations generally determine the optimum specific impulse and powe $r$ level, the pro- pulsion system weight as a function of these parameters should be a computer program input. With the final design point specification for an initial spacecraft system imminent, the weight analysis must be realistic. Overly optimistic or overly conservative estimates could result in a nonoptimum spacecraft design, unexpected payload loss, or the sacrifice of full capability.

The purpose of this paper is to describe the present state of SEP system technology, using the SEPST III hardware program as a baseline. The goals, design, and results of current testing will be described. This data combined with a review of element development in other organizations and a system scaling analysis, will indicate the readiness of the present SEP technology to meet spacecraft requirements in the $5-$ to $20-\mathrm{kW}$ power range. The SEP system expected weight dependence on specific impulse and power will be presented to show the relevance of present mission calculations to current hardware. A portion of the direct interactions of the SEP system with conventional spacecraft subsystems will also be discussed. The areas of interaction included are attitude control stability, electromagnetic noise, and power bus sipple.

\section{Basic Characteristics of the SEP System}

The SEP system has two principal functions: (1) to increase the spacecraft hyperbolic excess energy by converting solar energy into thrust, and (2) to provide spacecraft attitude control during the thrusting period. Although the basic SEPST propulsion system concept $(6-9)$ has not changed appreciably since 1966, continuing efforts to as semble a complete system have clarified and improved element and system design. The knowledge gained in element development since 1966 has been factored into the system design to take advantage of or to allow for changes in element performance. The SEP system concept is shown in Fig. 1. Primary power, derived from the solar array, is conditioned to meet mercury bombardment ion thruster requirements and is then converted into thrust power by acceleration of propellant. This inter-element relationship, including a switching matrix to improve system reliability and the controller for power manaing and logic functions, is the most fundamental and forms the major power loop. In flight, 


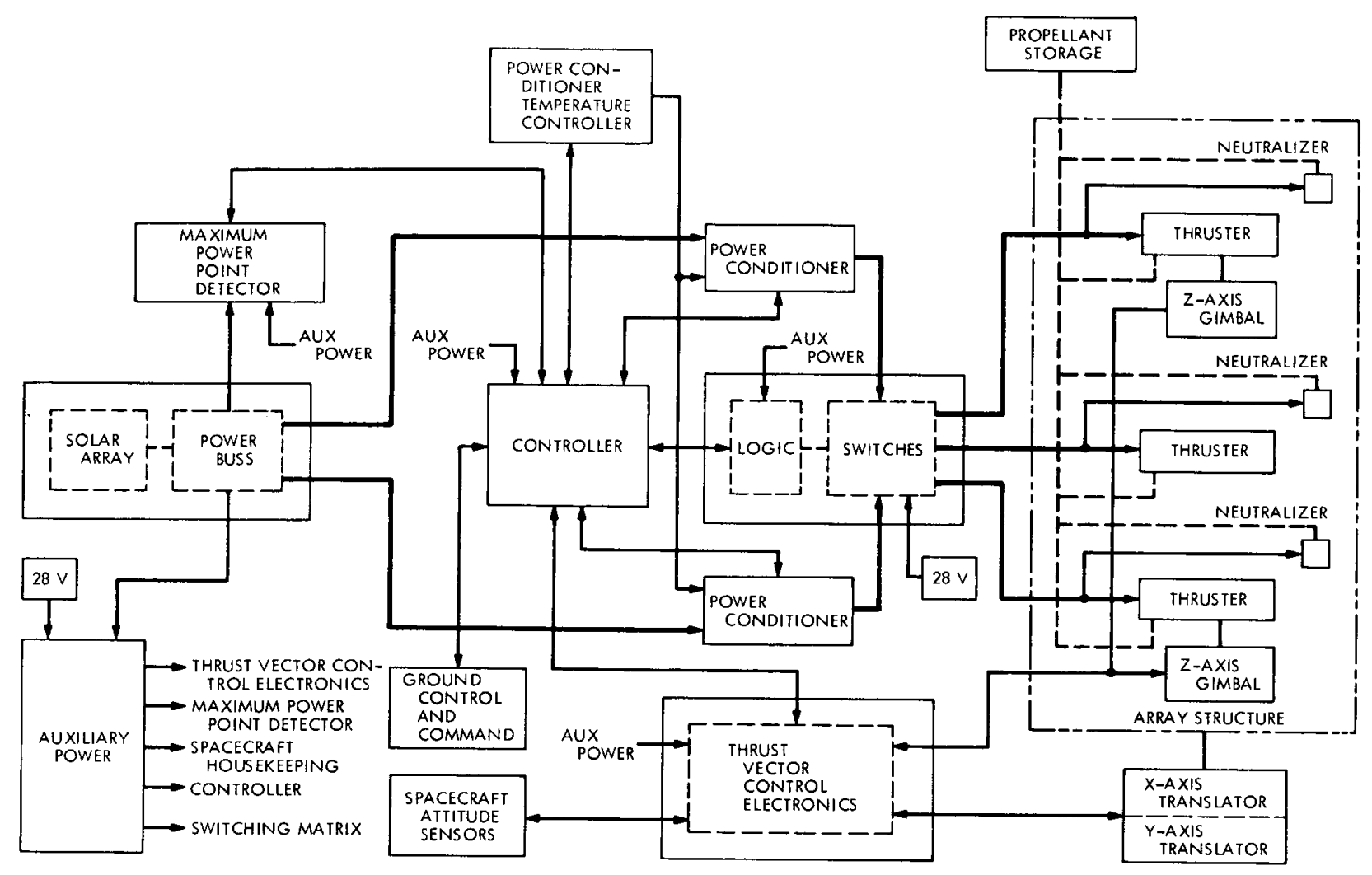

Figure 1. Propulsion System Block Diagram

the controller will be a part of the spacecraft central computer and sequencer $(C C \& S)$. The principal CC\&S functions related to the propulsion system include system start-up, thrust power profile programming, activation of the maximum power point detector, failure detection, correction including switching, and general system status monitoring. Power is also supplied to the auxiliary power unit and from it to other elements.

The second major system loop is formed by the attitude control star and sun sensors, the thrust vector control (TVC) electronics, and the TVCthruster array mechanism. The thrust vector is positioned by means of the mechanism to provide three-axis spacecraft attitude control using the primary thrust beam. Such a scheme has been shown to be lighter than a cold gas system. $(1,2,10)$ Studies, in addition to the present program, have indicated that two-axis array translation combined with one-axis thruster gimballing allows the lightest and simplest mechanization. $(1,10)$

\section{SEP Element Development Status}

The following section discusses specific element development status and presents recent test results. Conventionally, the SEP system is divided into the power (solar array and main power buss) and thrust subsystems. The present discussion is concerned primarily with the more complex thrust subsystem. However, because the two subsystems are highly interdependent, the expected characteristics of the power subsystem will be reviewed briefly.

The elements discussed in greatest detail are the thruster, power conditioning unit, thrust vector control subsystem, propellant storage, and switching matrix. Elements discussed in less detail include the solar array, maximum power point detector, auxiliary power unit, and system controller.

\section{A. Solar Array}

The application of SEP has depended for many years upon the development of lightweight solar arrays. Conventional fold-out, Mariner-type arrays weigh on the order of $50 \mathrm{~kg} / \mathrm{kW}$, which is far too heavy for use in SEP systems. Development of rollout arrays, which make SEP useful and cost effective, is presently in progress. A weight of $15 \mathrm{~kg} /$ $\mathrm{kW}(18.3 \mathrm{~kg} / \mathrm{kW}$ degraded) has been demonstrated by General Electric.(11) Such a solar panel is shown in Fig. 2. The solar cells are mounted to a flexible membrane that $c$ an be roll in and out similar to a window shade. A flexible boom and draw bar support the array in deployment.

The solar array is composed of photovoltaic semiconductor cells connected in series strings, with the strings connected in parallel through cou- 


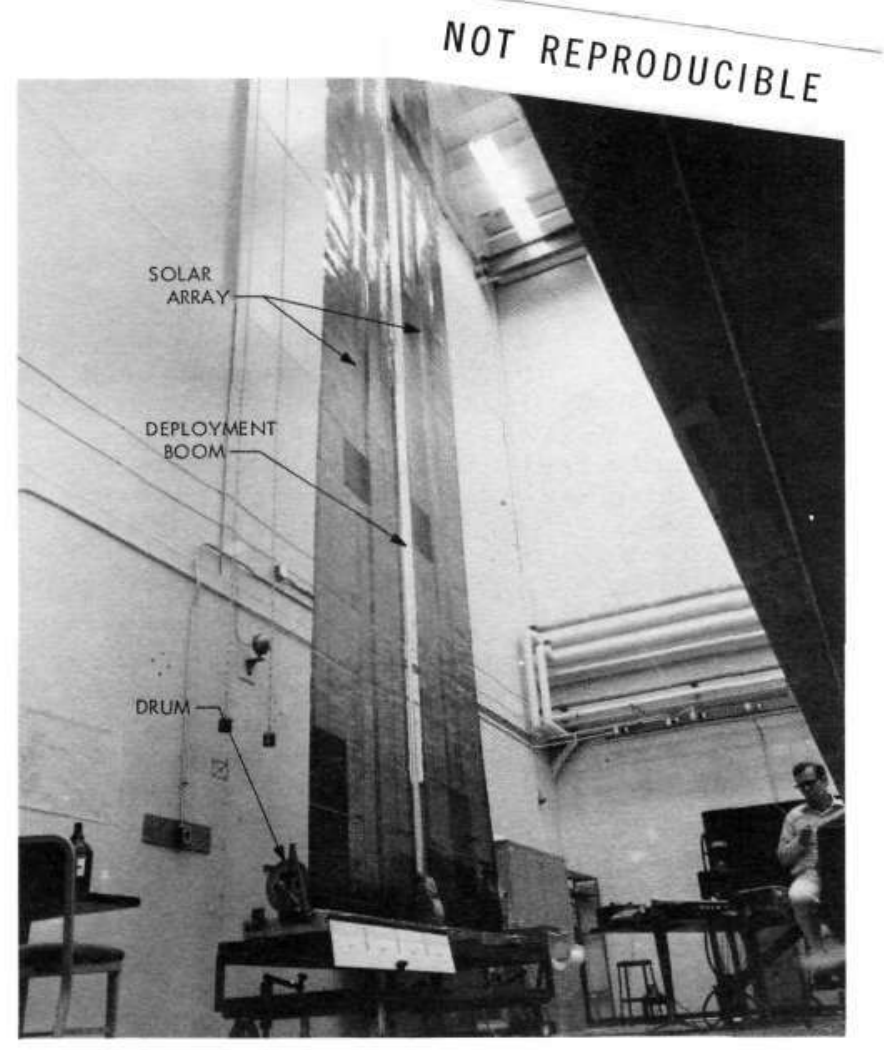

Figure 2. General Electric Roll-Out Solar Array

pling diodes. The desired voltage and current level can be produced by the proper connections. The conventional approach is to condition the raw solar power as required with a separate unit. However, another approach being investigated is the direct use of the raw power; $(12-14)$ that is, the solar array connections are tailored with switches to provide the required voltages and power levels. This technique is discussed further in the power conditioner (PC) section. At present, only conventional solar arrays are available and the SEP system will require separate power conditioning.

The solar array voltage is presently limited by PC power transistor technology. In conventional inverter operation, twice the input or array voltage is applied across the transistor. With a derating factor of 2, the solar array voltage is limited to about one quarter of the rated transistor voltage. Present PC designs limit the array voltage to $80 \mathrm{~V}$. Higher voltage transistors have been developed for industrial applications and soon may be qualified for space applications. The Delco DTS 704 (750 V, 3.5A) and Delco DTS 804 (800 V, 5A) are examples. These also have low-voltage drop $\left(\mathrm{V}_{\mathrm{ce}}\right.$, sat $)$ and can be used in a bridge circuit with two transistors in series. This scheme would bring the maximum array voltage to $400 \mathrm{~V}$, reduce transmitted currents, and improve system efficiency.
The available thrust power at any distance from the sun (R) can be expressed in the form(15)

$$
\mathscr{P}_{\mathrm{t}}(\mathrm{R})=\frac{\eta_{\mathrm{s}} \mathscr{P}_{1} \mathrm{~S}}{\mathrm{R}^{2}}
$$

where

$$
\begin{aligned}
\mathscr{P}_{\mathrm{t}}= & \text { thrust power at distance } \mathrm{R}, \mathrm{kW} \\
\mathscr{P}_{1}= & \text { nominal solar array power output at } \\
& 1 \mathrm{AU}, \mathrm{kW} \\
\mathrm{R}= & \text { sun-probe distance, } \mathrm{AU}
\end{aligned}
$$

The factor $\eta_{s}$ accounts for array power losses (e.g., cabling resistance and solar cell mismatching) and expected degradation due to radiation and micrometeorite damage. A value of $\eta_{s}$ of about 0.82 is anticipated. The factor $\mathrm{S}$ accounts for the expected change in solar cell efficiency with temperature changes and can be expressed in the form

$$
S=\frac{1}{R^{3 / 2}}\left(2.17-7.88 R^{1 / 2}+7.51 R-0.80 R^{3 / 2}\right)
$$

This equation applies for R between 0.6 and $5 \mathrm{AU}$. A point of maximum power is expected near 0.6 AU. (15) At R less than $0.6 \mathrm{AU}$, the array becomes too hot and must be canted to reduce incident radiation. Typical array output characteristics are shown in Fig. 3.

The solar array dynamic characteristics are also important in evaluating SEP system operation. Recent data ${ }^{\dagger}$ are shown in Fig. 4 for solar array impedance $(E / I)$ as a function of load variation frequency at a given array-voltage. As indicated, the array will follow the static E-I characteristics (Fig. 3) for load changes up to $20-30 \mathrm{kHz}$. The drop in impedance at higher frequencies reflects the energy storage ability (i.e., inherent cell capacitance) of the array. At high loading frequency, the array can supply current in excess of the average dc value at the same voltage and recharge the capacitance when the load current is lower than the average dc value.

This dynamic performance is important for several reasons. First, the power conditioners that handle most of the spacecraft power presently induce a $5 \%$ current and voltage ripple on the main power buss. Elimination of this ripple would require heavy filtering elements. Without filtering, if the ripple frequency is low (less than $30 \mathrm{kHz}$ ), a power margin of $5 \%$ would be required. Figure 4 indicates that a high-frequency ripple component (greater than $30 \mathrm{kHz}$ ) will not affect the average dc power capability of the array. This means that

\footnotetext{
*Engineering Data Sheets for DTS 704 and 804 Transistors, Delco Radio Div., G. M. Corp., January 1970.

†Schloss, A. , "Capacity (Farad Type) of Solar Cells and Panels Under Various Load Conditions," JPL Engineering Memo 342-91 (Revised), August 12, 1969.
} 


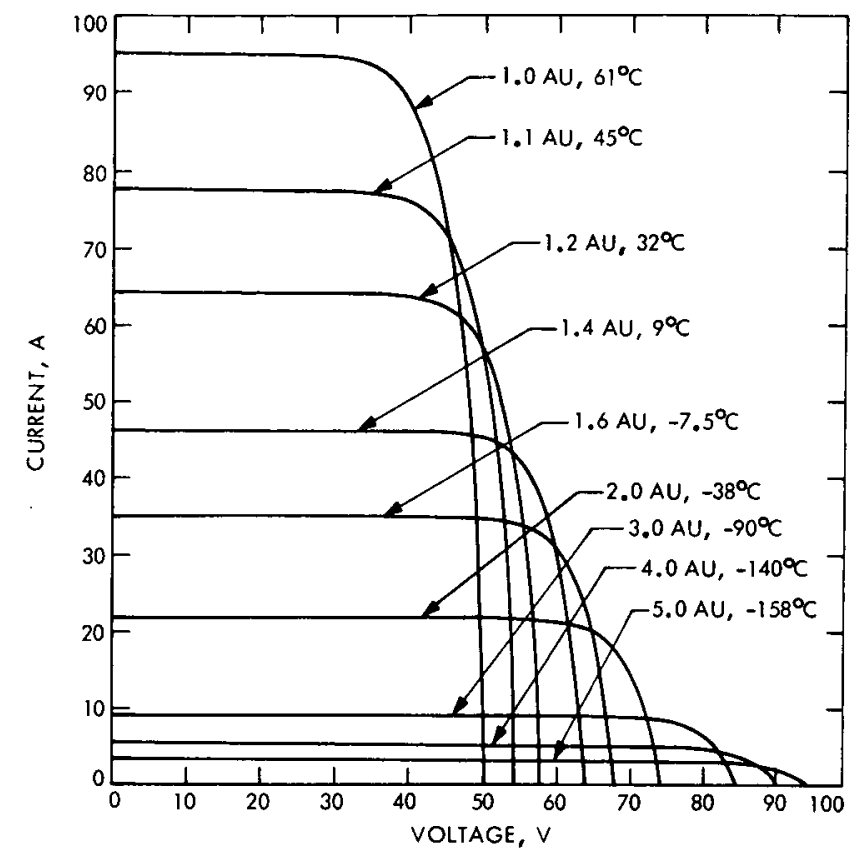

Figure 3. Solar Array Current vs Voltage Characteristic (Typical)

power demands, at high frequency, up to or beyond the maximum static capability will not necessarily destabilize array operation. The maximum ripple tolerable from this standpoint is determined by the inherent capacitance of the array.

The second consideration is the spacecraft auxiliary power unit. Any voltage ripple induced on the main power buss may disturb this conditioner. Filtering of the relatively small amount of auxiliary power (a few hundred watts) should be much easier than trying to eliminate the ripple source.

The third reason for interest in the array dynamic characteristics concerns the maximum power point detector (MPPD). The concept developed in SEPST III* is to rapidly and independently load the array and measure the point of maximum power capability. However, to trace the static E-I curve, the loading frequency must be less than about $20-30 \mathrm{kHz}$ to avoid an erroneous measurement.

\section{B. Maximum Power Point Detector}

The typical output characteristics can be shown for the solar panel (Fig. 3); however, the effects of ultraviolet radiation as well as proton and micrometeorite bombardment are not easily predicted. This uncertainty imposes a degradation factor of about $18 \%$ on the array output. The degraded power must be used in mission planning and by the propulsion system.
However, a day by day knowledge of the actual maximum power capability of the solar source would contribute substantially to present knowledge of the solar array. If the $18 \%$ degradation estimate is not accurate, the MPPD would be used to update the mission calculations.

The present technology of the Mariner and Surveyor type spacecraft relies upon data from selected sample solar cells. By observing the open-circuit voltages and the short-circuit currents and by measuring panel temperatures and $E-I$ values at the operating point, the maximum power point may be computed. However, the accuracy of such prediction is not better than $\pm 10 \%$.

It is well known that an attempt to operate the solar panel beyond the maximum power point ends in a collapse of the source voltage. The technique that is being developed within the SEPST program is designed to determine the maximum power point of the solar array accurately $( \pm 1 \%)$ without the necessity to shut down and restart the thrusters.* The principle followed consists of dividing the array into an arbitrary number of parallel sources (typically 12). These are diode coupled to the output terminal. To determine the peak power capability, the individual sources are sequentially resistively loaded and the peak power defined. The sum of all the individual readings gives the total peak power of the array. To avoid system shutdown when the power output of the overloaded section drops to zero, the thruster level is reduced by $1 / 12$ during the time of measurement (about 3 seconds).

\section{Thruster}

The SEP system depends strongly upon the thruster and the thruster operating characteristics. In the last few years, the mercury electron bombardment ion thruster has become highly developed and is presently ready for flight application. Thus, the SEP system discussed here is designed around this thruster. However, this thruster type has many possible cathode and ion optics configurations to be considered and evaluated. These configuration possibilities will be discussed to show the basis for the present choice of configuration.

Three types of cathode can be considered: oxide coated, mercury plasma (hollow), and liquid mercury. The cathode choice must consider development status, reliability/life, power requirements, testing convenience, and system integration.

The oxide coated cathode, which depends on thermionic emission from a coated metal surface, has been used extensively, is highly convenient, and presents the least integration difficulty. However, the life expectancy is rather low (500-1000 hr) and the power requirement is high $(100-200 \mathrm{~W}) .(16)$

\footnotetext{
"Schloss, A., "Capacity (Farad Type) of Solar Cells and Panels Under Various Load Conditions," JPL Engineering Memo 342-91 (Revised), August 12, 1969.
} 


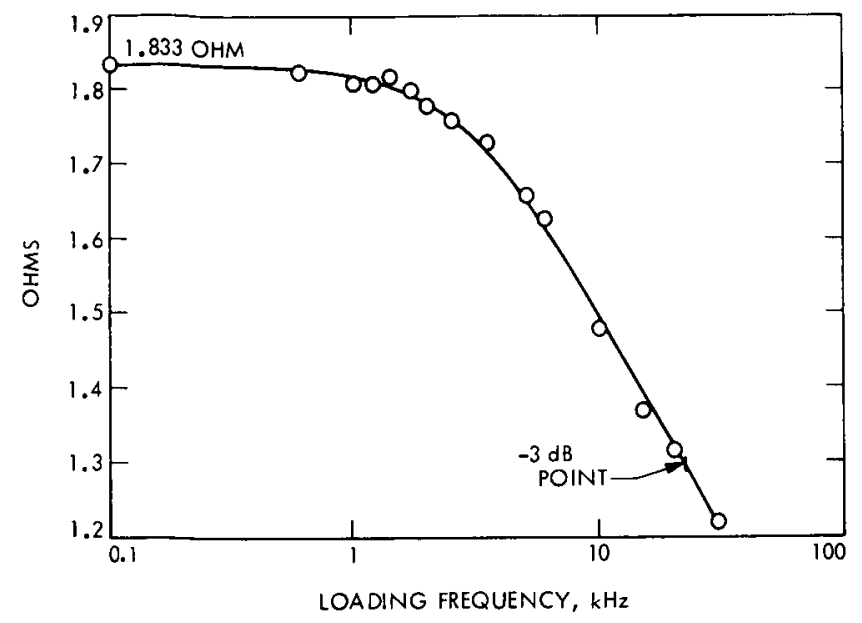

Figure 4. Solar Array Impedance as a Function of Loading Frequency

The hollow cathode, which also appears to utilize the thermionic emission process, has been tested in many laboratories and is used on SERT (space electric rocket test) II. Mercury-vapor flow through the cathode is required for normal operation. This flow apparently produces an intense discharge within the cathode and provides radiant and bombardment heating. After the cathode emission reaches a few amperes, external heating is not required. In addition, the hollow cathode is relatively small and requires only 20-30 $\mathrm{W}$ of heating power for starting. In comparison with the oxide cathode, the hollow cathode has improved life $(5,000-10,000 \mathrm{hr})^{(17)}$ and lower power, but has more difficult testing and system integration requirements due to the additional feed system.

The liquid mercury cathode (LMC) for ion thrusters has been developed entirely at the Hughes Research Laboratories.(18) Electron emission originates at an arc spot in the liquid mercury pool. Integration of the LMC thruster with control loops and a power conditioner is approximately a year behind the hollow cathode thruster. The LMC has demonstrated long life, requires no heating power, and requires only one main feedline. However, high voltage isolation of the propellant and thruster is more complicated because liquid flow $r$ ather than vapor must be isolated and the flow control is rather pressure sensitive.

With these factors in mind, the hollow cathode has been chosen for the present system testing. It is the most highly developed cathode with high-life capability and low-power requirements. With further development, the LMC is expected to become competitive with the hollow cathode.

Two ion optics system types are presently under consideration for use with the thruster. The first is the conventional two-grid system (screen and accelerator). With proper design, the two- grid type will operate with a specific impulse from $2500 \mathrm{sec} u p$ to any value required for expected missions (up to $5000 \mathrm{sec}$ ).(9) Grid life is determined only by accelerator thickness.

The second ion optics type is the insulated or coated grid concept. $(19,20)$ This scheme eliminates the screen grid that ordinarily provides the discharge plasma boundary. The plasma boundary is provided by an insulated coating on the accelerator. Present designs utilize a glass coating, although ceramic coatings have been proposed. The coated grid concept operates over the specific impulse range of 2100 to $3300 \mathrm{sec}$ and would extend the specific impulse range of the two-grid system. The principal difficulties are the fabrication of high-purity coatings, the frailty of the coating after fabrication, and the testing in ground facilities where sputter contamination is significant. Lifetimes up to about $500 \mathrm{hr}$ have been achieved with the coated grid. $(19,20)$

The two-grid ion optics system has been adopted for the present system. The required range of specific impulse, life, and mechanical strength are available without special fabrication processes. The coated grid method may become commonly available with further development.

The thruster (SE-20D) developed for the present SEPST system is shown in Fig. 5. This design is similar to the one $(\mathrm{SE}-20 \mathrm{C})(9)$ presented previously but includes a hollow cathode, with a complete feed system voltage isolation and a mercury neutralizer. Details of the main hollow cathode assembly (Fig. 5) and typical performance and operating characteristics will be given in Ref. 21 . Thruster performance will be considered later in this section. Details of the neutralizer assembly, hollow cathode isolator, packaging, and thermal integration will be presented here. Integration into a multi-thruster system using common propellant storage requires all thruster feedlines to utilize isolators although this produces major complications in thermal and mechanical packaging. The isolators, although not limited to the designs shown in Fig. 5, become an integral part of any final thruster design.

Initially, a cesium plasma bridge neutralizer was used in the present program. $(9,22)$ Cesium, which produces a low-work function cathode, resulted in relatively low starting-power requirements, low beam-neutralizer coupling voltage, and a low cesium flowrate. However, cesium is rather inconvenient for laboratory testing because of its reactive nature. Problems were encountered in evacuating the cesium reservoir (to avoid pushing liquid cesium out of the cathode) during vacuum chamber pumpdown and in avoiding contamination during chamber venting. In addition, the individual cesium reservoirs with an integral cathode assembly made neutralizer packaging and integration difficult.

In considering the alternate neutralizer, the mercury hollow cathode plasma bridge, the considerations were cathode power, coupling voltage, 

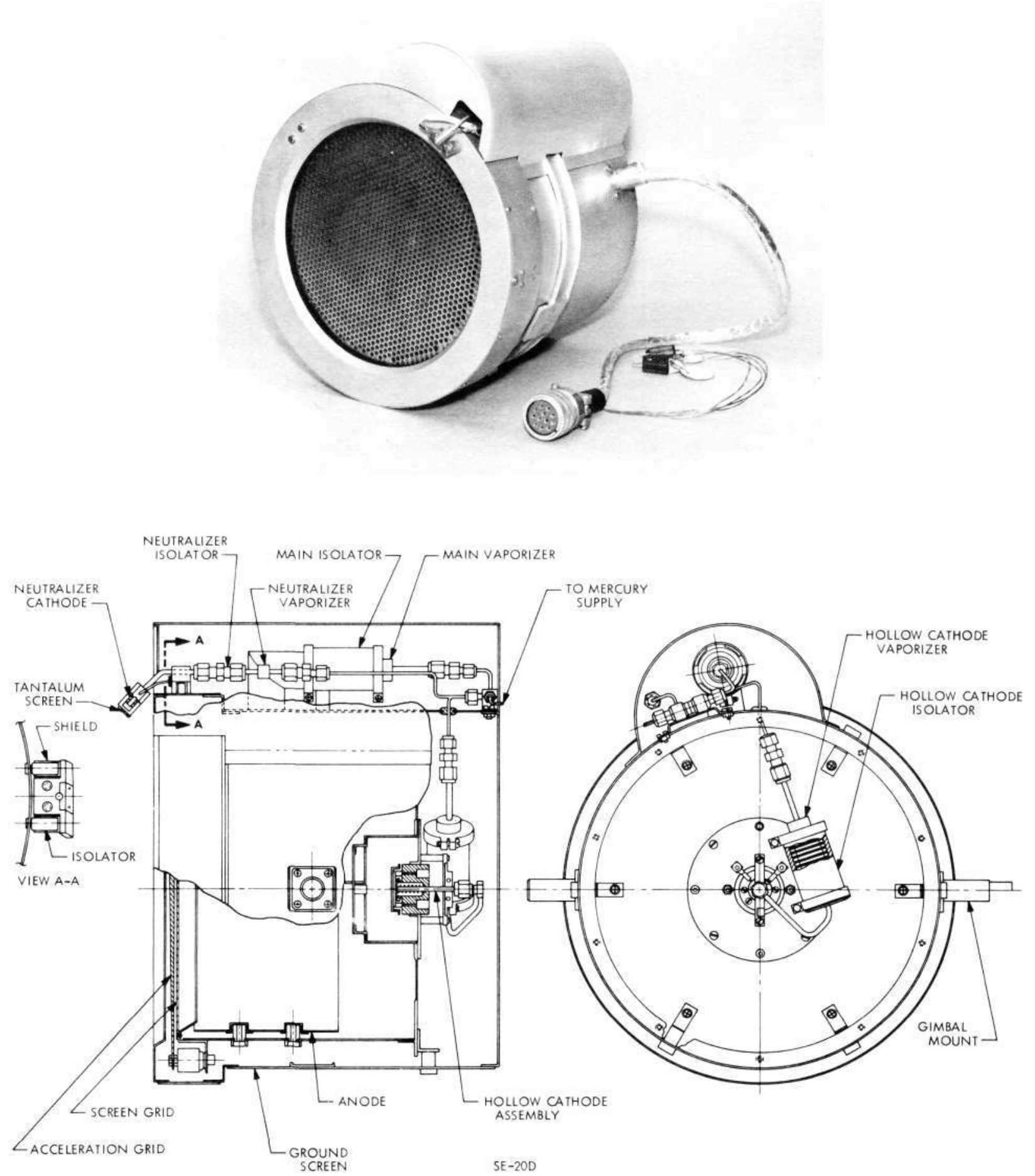

Figure 5. JPL 20-cm Diameter Thruster

flowrate, integration, and propellant tankage mass (3\% of the propellant mass for mercury against $50 \%$ for cesium). The extra cesium required because of individual reservoirs per thruster must also be included. A mercury neutralizer requiring approximately double the flnwrate of a cesium neutralizer is equivalent in the total propellant plus tankage mass required. For coupling similar to that with cesium, the flowrates with the mercury neutralizer are on the order of $4 \%$ of the main flow 
at full power. Including the testing factor, the flexibility in packaging, and low starting power, the mercury neutralizer using the main mercury supply appears to be the better choice.

The present neutralizer assembly is shown in Fig. 5. The cathode is a conventional mercury hollow cathode type, similar to that used on SERT II, and has a $0.02-\mathrm{cm}$ diameter tip orifice. The keeper electrode is mounted directly to the cathode and is insulated from the ground screen by the insulators shown. This configuration provides convenient as sembly, alignment accuracy, and a cathode radiation shield. Two neutralizer assemblies of the type shown in Fig. 5 have been tested and were found to perform similarly. A coupling voltage of 12 to $15 \mathrm{~V}$ was obtained with neutralizer flowrates of about $0.4 \mathrm{~g} / \mathrm{hr}$.

The neutralizer isolator requires only lowvoltage insulation (typically less than $50 \mathrm{~V}$ ). Since this value is less than the minimum breakdown voltage in mercury vapor $(400 \mathrm{~V})$, most any insulating method is satisfactory. The device shown in Fig. 5 is a standard teflon Swagelock coupling. Similar couplings made of nylon melted and those made of boron nitride were broken by the ferrules during compression.

The hollow cathode isolator, as with the main isolator, must insulate $2 \mathrm{kV}$. However, the vapor in the hollow cathode feedline is at higher pressure (a few tens of tor $r$ ) than the main feedline 10.05 tor $r$ ). The pressure in the main isolator is low enough to prevent voltage breakdown. The pres sure in the hollow cathode requires additional consideration. The technique shown in Fig. 5 uses a series of insulating spacers and disks of screen material to form compartments of short length. If a small amount of leakage occurs through the isolator, the voltage gradient will be relatively linear along the isolator. Thus, each of the compartments is required only to support a fraction of the total voltage. If this fraction is less than the minimum breakdown voltage, isolation is obtained for all pressures. This technique has been used successfully by researchers at Electro-Optical Systems, Inc. (23) and at Hughes Research Laboratories. (20) Approximately 500 hours of testing have been accumulated with two isolators of the design shown in Fig. 5 with leakage currents of less than a microampere. The present design will be further developed to reduce size and weight.

The packaging illustrated in Fig. 5 was intended to provide the minimum thruster length, including a ground shield. The cathode assembly, at high voltage, requires a feedline connection and is used as a basis for determining the package length. The hollow cathode isolator and vaporizer conveniently lay across the back. The three feedlines are then located in mutual proximity and join a common manifold. The main feedline and neutralizer are covered with a common ground screen. All wiring, except the magnet wire, is insulated with TFE type Teflon. The wiring, in the form of ribbon cable, must be flexible to accommodate thruster gimballing. This feature will be discussed further in conjunction with the TVC mechanism.

The use of the hollow cathode creates a packaging problem that is a major effort of the thruster design and is basically a two-part problem. First, the high-pressure hollow cathode vapor feedline is subject to condensation, particularly during startup. Since the vaporizer and cathode heaters are designed for efficient operation without providing for auxiliary preheating of the line and isolator, the heaters require up to several hours to raise the feedline temperature above the condensation point (about $150^{\circ} \mathrm{C}$ ). By the time the feedline is up to temperature allowing the thruster to start, a substantial amount of mercury has condensed. As the thruster and feedline warm up further from heating by the discharge, the temperature of the feedline controls the hollow cathode flow. Until all the condensed propellant is used, the hollow cathode vaporizer has no control over thruster operation.

The second part of the problem concerns steady-state operation. When operating at full power, the thruster housing temperature is about $250^{\circ} \mathrm{C}$. If the hollow cathode feedline is fully enclosed with the ground screen, the vaporizer also reaches this temperature. This level is the vaporizer normal operating temperature and is no longer controlled by the heater element. Thus, there are two opposing requirements: (1) adequate heat transfer to the feedline with low transfer away for startup and (2) low heat transfer to and/or high heat transfer away during steady-state operation. Two approaches are apparent. First, the feedline can be well insulated from the thruster to reduce heat input during steady state. The long startup time must be acceptable. Second, sufficient cooling paths can be provided for steady-state operation with additional preheating power provided during startup. This second approach has the advantage in that it solves both the thermal balance and condensation problems.

Prior to the initiation of the thruster discharge, the discharge power supply, ordinarily with several hundred watt capability, is available for preheating. A series of heating elements on the thruster and cathode feedline has been used in conjunction with a Klixon thermal switch. The thermal switch, mounted to the rear surface of the thruster (switch in the open or hot position), removes the heaters from the circuit.

The $20-\mathrm{cm}$ diameter thruster as described in this section provides a. reference point for further analysis. Units of this type (Fig. 5) presently weigh about $4.5 \mathrm{~kg}$. Lighter gauge materials are expected to reduce this weight to about $4.1 \mathrm{~kg}$.

To obtain an estimate of the total system mass, the minimum number of thrusters required, as well as thruster mass, must be specified. If the constraint is imposed that all thrusters in the system be identical, for power matching (i.e., utilization of all available solar power by the thrust subsystem), the minimum number of thrusters 
operating at the minimum power point is given by the smallest integer $n$ that satisfies

$$
\mathrm{n} \geq \frac{1}{\alpha_{\mathrm{t}}-1}
$$

provided $S / R^{2}<1 / \alpha_{t}$; otherwise $n=1$. The throttling factor $\alpha_{t}$ is the ratio of thruster full power to lowest operable power. The limit on minimum operating power and, hence, on $\alpha_{t}$ is determined by thruster characteristics. (Thruster throttling will be discussed later in this section.)

The minimum number of identical thrusters operating at the maximum power point is then given by the smallest integer $k$ that $s$ atisfies

$$
k \geq \frac{\mathscr{P}_{\max }}{\mathscr{P}_{\min }}\left(\frac{\mathrm{n}}{\alpha_{\mathrm{t}}}\right)
$$

or

$$
k \geq\left(\frac{\mathrm{S}}{\mathrm{R}^{2}}\right)_{\max }\left(\frac{\mathrm{R}^{2}}{\mathrm{~S}}\right)_{\min }\left(\frac{\mathrm{n}}{\alpha_{\mathrm{t}}}\right)
$$

The individual thruster maximum power level $p_{t}$ is then given in $\mathrm{kW}$ by

$$
\mathrm{p}_{\mathrm{t}}=\frac{\mathscr{P}_{\max }}{\mathrm{k}}
$$

Calculations based on the JPL SE-20C thruster(24) design have resulted in the following equation for thruster mass:

$$
m_{t}=1.85+57 D_{b}^{2}
$$

where

$$
\begin{aligned}
& \mathrm{m}_{\mathrm{t}}=\text { individual thruster mass, } \mathrm{kg} \\
& \mathrm{D}_{\mathrm{b}}=\text { ion beam diameter, } \mathrm{m}
\end{aligned}
$$

The design maximum ion beam current density is $32 \mathrm{~A} / \mathrm{m}^{2}$. This value is about $30 \%$ below the maximum short-term capability of present thrusters. The derated value is used in this analysis because of the present uncertainties in beam divergence and accelerator grid life. The beam diameter, using $32 \mathrm{~A} / \mathrm{m}^{2}$, can be written

$$
D_{b}=\frac{6.30 \times 10^{2}}{I_{s p}}\left(\eta_{m} \eta_{t} p_{t}\right)^{1 / 2}
$$

where

$$
\begin{aligned}
I_{s p} & =\text { true specific impulse, sec } \\
\eta_{m} & =\text { propellant utilization efficiency } \\
\eta_{t} & =\eta_{m} \eta_{p}=\text { total thruster efficiency } \\
\eta_{p} & =\text { power efficiency } \\
p_{t} & =\text { maximum thruster power, } \mathrm{kW}
\end{aligned}
$$

Combining Eqs. (6) and (7), we obtain

$$
\mathrm{m}_{\mathrm{t}}=1.85+2.26 \times 10^{7} \frac{\eta_{\mathrm{m}} \eta_{\mathrm{t}} \mathrm{p}_{\mathrm{t}}}{\mathrm{I}_{\mathrm{sp}}^{2}}
$$

With the use of multiple identical thrusters, the total number is given by

$$
\mathrm{N}_{\mathrm{t}}=\mathrm{n}_{\mathrm{t}}+\mathrm{n}_{\mathrm{s}}
$$

where

$$
\begin{aligned}
& n_{t}=\text { maximum number of thrusters operating } \\
& \text { at any time } \\
& n_{s}=\text { number of initial spare thrusters }
\end{aligned}
$$

with the definitions,

$$
\mathscr{P}_{\mathrm{t}}=\mathbf{n}_{\mathrm{t}} \mathbf{p}_{\mathrm{t}}
$$

and

$$
\mathscr{P}_{\mathrm{t}}=\eta_{\mathrm{c}} \mathscr{P}_{\mathrm{c}}
$$

where

$$
\begin{aligned}
& \mathscr{P}_{\mathrm{c}}=\text { total unconditioned power, } \mathrm{kW} \\
& \eta_{\mathrm{c}}=\text { power conditioner efficiency }
\end{aligned}
$$

The total thruster mass is given by

$$
M_{t}=1.85\left(n_{t}+n_{s}\right)+2.26 \times 10^{7} \frac{\eta_{m} \eta_{t} \eta^{\mathscr{P}} c}{I_{s p}^{2}}\left(1+\frac{n_{s}}{n_{t}}\right)
$$

In addition, Eq. (7) can be written in terms of $\mathscr{P}_{\mathrm{c}}$ as

$$
D_{b}=\frac{6.30 \times 10^{2}}{I_{s p}}\left(\frac{\eta n^{\eta \eta_{c}{ }^{\mathscr{P}}}{ }_{\mathrm{c}}}{n_{\mathrm{t}}}\right)^{1 / 2}
$$




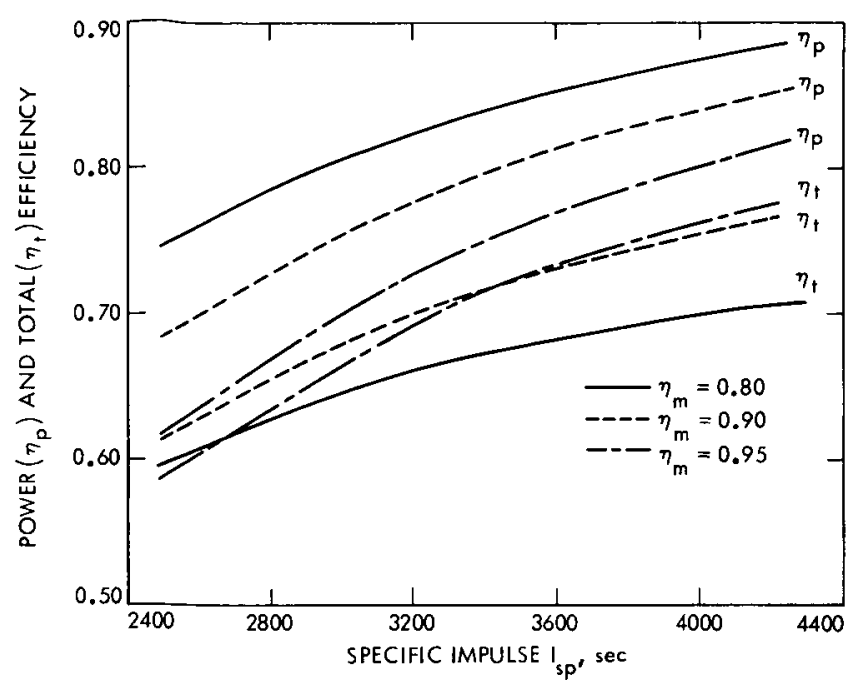

Figure 6. Thruster Power Efficiency and Total Efficiency as a Function of Specific Impulse

A similar analysis has been presented in Ref. 25 for the case of nonidentical thrusters. However, for most practical situations, it is expected that identical units would be used.

Thruster power efficiency $\left(\eta_{p}\right)$ and total efficiency $\left(\eta_{t}\right)$, for the present technology, are presented in Fig. 6 as a function of true specific impulse. As shown, propellant utilization efficiencies near $90 \%$ produce optimum total efficiency.

The throttling characteristic of present thrusters is shown in Fig. 7. Throttling factors $\left(\alpha_{t}\right)$ up to 3 can be achieved, but a total efficiency loss of about $7 \%$ is incurred. The efficiency loss is about $3 \%$ for an $\alpha_{t}$ of 2 .

\section{Power Conditioner}

In discussing the solar array, it was noted that two basic approaches to conditioning the raw power are being considered. The "integral" PC approach (in conjunction with high-voltage arrays) has been proposed most recently, while the "separate unit" $P C$ approach is more conventional and is used in the present SEPST program. The integral approach, carried only through feasibility studies at this time, $(12-14)$ is an attempt to eliminate weight and possibly improve conditioning efficiency by producing the required power supplies, including the highvoltage supplies, from digitally controlled solar cell arrays. The feasibility study reports are not available at the time of this writing and a discus sion of this approach cannot be presented here. However, considering the complexity, integration, reliability, and manufacturing problems of such a system, the integral PC technology will probably require several years of development before reaching the status of conventional power conditioning.
Conventional or separate unit conditioning, using either transistors or thyristors as switching elements, can be approached in two ways. First, since input line regulation is required by array voltage changes (see Fig. 3), the regulation could be performed on the total power in a modularized unit separate from the thruster PC. The positive feature of this two-unit technique is that the solar array could be standardized for a multimission spacecraft (inbound or outbound). Only the basic line regulator would need modification for different missions. However, this multi-mission convenience is offset by an expected total PC weight increase of about $30 \%$ over the one-unit approach.

The second method of separate unit PC approach performs the line regulation within the individual power supplies, using pulse width or frequency modulation. Although this method provides a simple and efficient regulation scheme, the design depends strongly on the range of input voltage variation. The switching elements (transistor or thyristor current capability at the low line voltage determines the maximum power rating of each inverter. In order to maintain high efficiency with transistors, switching times must be fast (on the order of $5 \times 10^{-7} \mathrm{sec}$ ). This speed can be obtained presently with $325 \mathrm{~V} / 20 \mathrm{~A}$ transistors.(26) Thus to meet the efficiency and power requirements, the high-power portion of the transistor system is constructed in modular form with each module producing $250-W$ nominal power with capability for $300 \mathrm{~W}$ maximum $(40 \mathrm{~V} / 7.5 \mathrm{~A}$ or $80 \mathrm{~V} / 3.75 \mathrm{~A})$. This modular approach is basically lighter for a given reliability than a single inverter (which could be built only with slow transistors) because partial redundancy $c$ an be used. If input voltages lower than 40 volts were to be used, the present transistors would exceed the maximum derated current and, for a given total power, additional modules would be required.

As noted in Ref. 5 , the 4 to 1 voltage range required by multi-mission spacecraft presently cannot be accommodated by the transistor PC unit without a large weight penalty. Alternate approaches, such as the "energy ladling"(27) or the series inverter $(28)$ concepts could also be used.

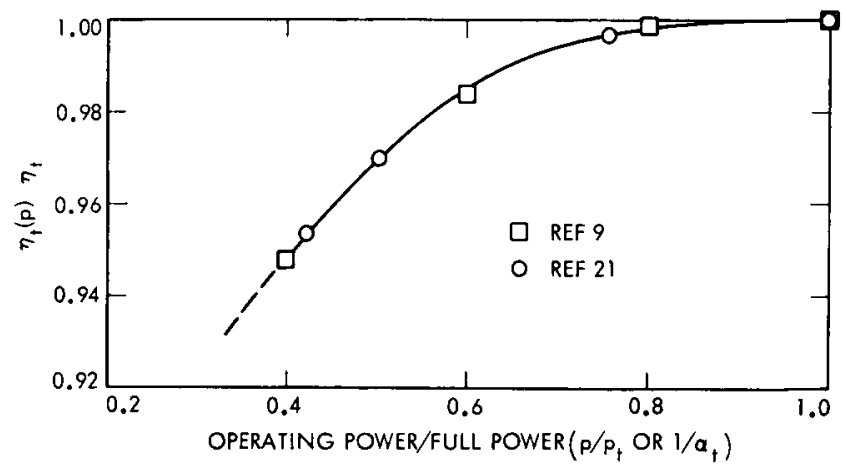

Figure 7. Thruster Throttling Characteristics 
However, these concepts have not been fully developed for transistors.

The situation with thyristor switching elements is $r$ ather different from that for transistors. The present units can switch up to $500 \mathrm{~A}$ at $1200 \mathrm{~V}$. Thus, the 4 to 1 input voltage range is well within the thyristor capability without large weight penalties. However, this device has a slow switching speed (milliseconds) and must be used carefully to avoid large switching losses. A program to demonstrate efficiency and weight capabilities of a thyristor PC was conducted at TRW, initially managed by NASA-ERC and subsequently by NASALeRC.

The present thyristor design approach uses a series inverter producing a sinusoidal ac output. (28) This design is incontrast with the parallel inverter technique, which produces a nominal square wave output. The sinusoidal wave form results in low switching losses, even though the switching speed is low, since voltage is switched with near zero current. However, the low switching losses may be offset by the saturation, or resistive, losses that are high relative to transistors. In addition, since a single inverter is used to produce the screen, or high power, a large ripple may be induced on the input line. Line regulation is achieved by pulse width modulation. This technology appears to be a year or more behind that of transistor power conditioning.

As implied throughout the previous discussion, the present SEP system uses modularized transistor inverters. The modular design has benefits in addition to reliability. All modules can be mounted on a single panel allowing direct radiation to space. The panel structure is not required for heat transfer and is only constrained to meet launch loads. The weight is well distributed on the panel allowing a light structure design.

Transistor power conditioner development, using self-radiation cooling and a modular screen supply design, has been in progress since 1964 at Hughes Aircraft Company (HAC). The first unit (termed $\mathrm{BB}-\mathrm{O}$ ) was designed for the oxide cathode thruster and did not include precise regulation(29) ( $\pm 5 \%$ regulation with $\pm 20 \%$ line voltage change). Regulation of the screen supply (about $80 \%$ of the $\mathrm{PC}$ power) was obtained by switching inverter modules in or out of the circuit. A 500-hr thermal vacuum test was performed with a SERT II thruster (at about $1.5 \mathrm{~kW}$ ). This PC was then modified to operate a 2.5-kW thruster. (16) This work established control loop operation and techniques for PC recycle during thruster arcing.

The unit has been further modified (to BB-OM) at JPL to operate the hollow cathode thruster. (30) Tests are presently in process to study recycle and control problems of the hollow cathode thruster.

In view of the requirements for lightweight, high efficiency, low induced input line ripple, and line regulation, the development of a second power conditioner was started in 1968.(26) Designed for an oxide cathode, this unit incorporated control and recycle procedures previously established, and utilized the more advanced electronic components then available. The first unit (BB-1) was delivered in June 1969 for evaluation and is shown in Fig. 8.

The BB-1 design(26) uses eight parallel type, pulse width modulated inverters for regulating (40- to $80-\mathrm{V}$ line) the $2-\mathrm{kV}$ screen output voltage to $\pm 1 \%$. The drive to each inverter is staggered (16 phase) to minimize output ripple. The inverter switching frequency is $10 \mathrm{kHz}$, producing a ripple frequency of $160 \mathrm{kHz}$. Output ripple is $\mathrm{L}-\mathrm{C}$ filtered to $\pm 5 \%(100 \mathrm{~V})$. Ripple induced on the input line is filtered to about $\pm 5 \%(2 \mathrm{~V})$. Since the screen consumes $80 \%$ of the power, the screen contributes most of the input line ripple at $160 \mathrm{kHz}$. In reviewing Fig. 4, a solar array loading frequency of this magnitude should not seriously affect the array voltage. However, the electromagnetic radiation associated with such loading on the large array must be investigated.

Evaluation of the BB-1 unit was completed in November 1969.(31) Testing for about 1300 hours proved the success of the design and only minor modifications were required. The first 800 hours of testing were accompanied by frequent disruptions

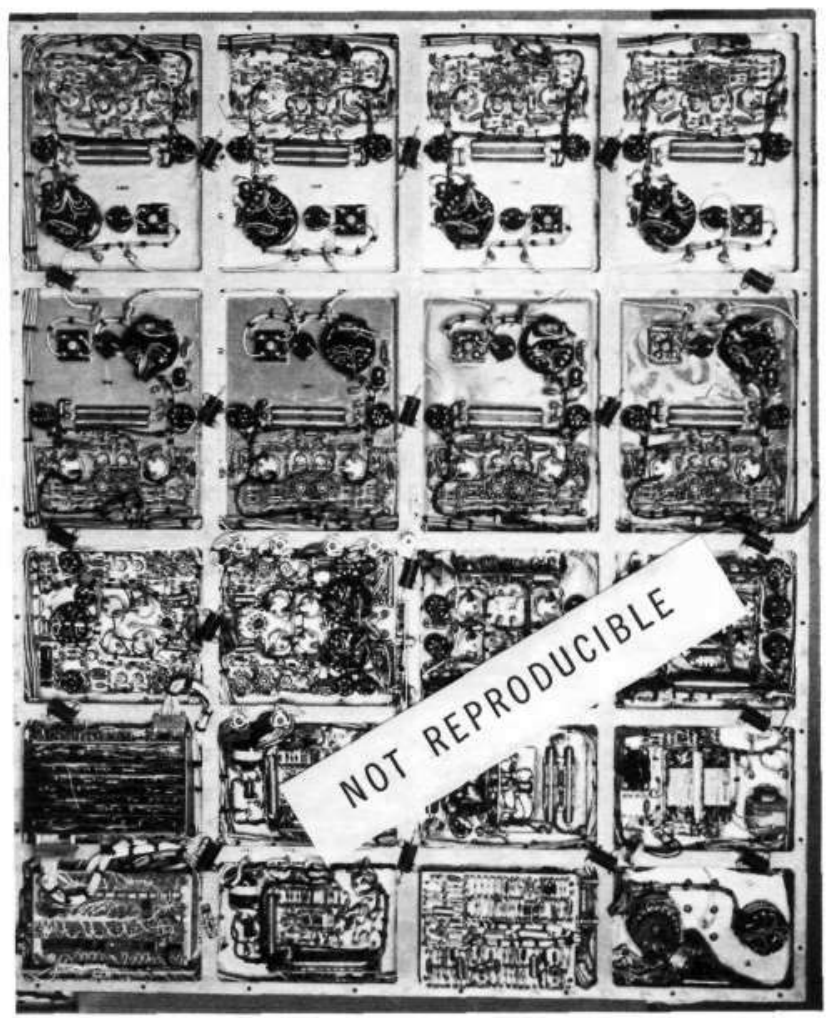

Figure 8. Hughes Aircraft Co. Power Conditioner (Model BB-1, 2.75-kW Input) 
of the control functions during thruster arcing. Measurements indicated that voltage transients on the $5-\mathrm{V}$ logic buss were causing integrated circuits to operate unexpectedly. This difficulty was corrected by: (a) separating the power return and signal return lines, which were originally connected in series, and (b) adding L-C filtering in several locations in the control module. After these modi fications, a 500-hr test was successfully completed with only normal manual control required for power set point changes. During this $500-\mathrm{hr}$ period, approximately 10,000 recycles occurred due to thruster arcing. The major portion of the 500 -hr test, as with the previous $800 \mathrm{hr}$, was run at full output power $(2.6 \mathrm{~kW})$. The severe thruster arcing was caused by sputter coating on thruster body-ground screen insulators. The perforated thruster ground screen then used has been replaced with a solid cover, as indicated in Fig. 5 .

The BB-I unit was modified by HAC to operate the hollow cathode thruster. Evaluation of this unit (BB-1M) was completed in December 1970. Two additional units, EX-1 and $E X-2$, were delivered in Eebruary 1971 and system integration was completed in July 1971. The EX-1 and EX-2 units weigh about $13.3 \mathrm{~kg}(4.9 \mathrm{~kg} / \mathrm{kW}$ of input power).

The specific mass of current technology PC units can be expressed in the form $(26,29)$

$$
\frac{m_{c}}{p_{c}}=3.8+7 e^{-0.7 p_{c}}
$$

where

$$
\begin{aligned}
& m_{c}=\text { mass of a single unit, } \mathrm{kg} \\
& \mathbf{p}_{c}=\text { power input to } \mathrm{PC} \text { unit, } \mathrm{kW}
\end{aligned}
$$

For a total system with multiple identical thrusters and PC units, the total PC mass can be expressed as

$$
M_{c}=\left(1+\frac{n_{p}}{n_{c}}\right)\left(3.8+7 e^{-0.7 \mathscr{Q}}{ }_{c} / n_{c}\right)_{\mathscr{P}_{c}}
$$

where

$$
\begin{aligned}
& n_{c}=\text { number of initially operating } P C \text { units } \\
& n_{p}=\text { number of initially spare PC units } \\
& \mathscr{P}_{c}=\text { total power into PC units }
\end{aligned}
$$

The area of the PC unit (required for radiation) is determined by efficiency and transistor maximum temperature. For long life, this temperature must be $25-35^{\circ} \mathrm{C} .(26)$ At $25^{\circ} \mathrm{C}$, the PC can radiate to space approximately $400 \mathrm{~W} / \mathrm{m}^{2}$. The power to be radiated per unit is

$$
\mathscr{P}_{\mathrm{r}}=\left(1-\eta_{\mathrm{c}}\right) \mathscr{P}_{\mathrm{c}}
$$

where $\eta_{\text {c }}$ is the PC efficiency. The area required for radiation is (in $\mathrm{m}^{2}$ )

$$
A_{c}=2.5\left(1-\eta_{c}\right) \mathscr{P}_{c}
$$

Calculated efficiencies up to $93 \%$ have been predicted for both transistor (26) and thyristor (28) PC units. The measured full power efficiency of the BB-1 unit is about $89 \%$ based on input dc volt amps.(31) The addition of higher efficiency transistors is expected to bring the efficiency into the low $90^{\prime} \mathrm{s}$.

\section{E. Auxiliary Power}

The auxiliary power unit is normally used on a spacecraft to supply engineering and science loads. In an SEP system, it has the additional requirements of supplying the electronics of the PC (for initially establishing logic buss voltages), the switching matrix (for stepper motor and logic module power), and the MPPD. The propellant storage (pressure transducer), controller, and TVC electronics are also ordinarily supplied by this unit.

In the present development program, this element is used primarily for convenience and to determine SEP system power demands. A Mariner type $2400-\mathrm{Hz}$ inverter with $35-\mathrm{V}$ input was purchased. To accommodate the solar array line voltage variation, a line regulator designed for the PC was built. To add reliability in endurance testing, another $2400-\mathrm{Hz}$ inverter with $115-\mathrm{V}$ ac input is connected in parallel as a standby. The auxiliary power unit is built and ready for system testing. The SEP system share of this unit weight is estimated to be about $4 \mathrm{~kg}$ ( $10 \%$ of the Mariner auxiliary power unit).

\section{F. Switching Matrix}

To evaluate the technology status of all system elements, the switching matrix (see Fig. 1) has been investigated. The ultimate decision to use this element depends upon the reliability of the thrusters and power conditioners. When system reliability with the added complexity of the switches exceeds the reliability of the non-interchangeable thruster-PC system, switching is advantageous. The tradeoff of switch weight against additional PC units is of second order relative to reliability considerations. The present use of switches does not imply a firm requirement for future systems. However, considering the desirability of failure detection (i.e., PC or thruster failure), switching a PC between its thruster and dummy loads would be a minimum requir ement. 
Two types of switches have been investigated: mechanical and solid state.(32) Solid state switching (using thyristors) is undesirable because of higher losses of the thyristors and the lower reliability due to a high parts count and complex control circuitry. The weight of both types of switching appears to be comparable. The mechanical stepping type switches used in the present program have been discussed previously.(16) However, the individual switches have been hermetically sealed for operation in vacuum. Commercially available switches presently employed require the use of two units per PC. Each switch has four decks with two wipers per deck. Each wiper can be connected to one of six positions. Thus, up to five thrusters can be accommodated with one position for the dummy load. The stepper motors require $28-\mathrm{V}$ dc power. Each switch weighs about $1 \mathrm{~kg}$ or $2 \mathrm{~kg}$ per PC.(33) It is expected that the redesigned flighttype switch for one PC would weigh about $1.5 \mathrm{~kg}$.

The logic module required to actuate the switch, to determine switch position, and to prevent incorrect connections, is presently an individual unit. This unit could be incorporated into the controller in a flight system. The logic module is connected to a manual control and display panel (MCDP). In manual operation, push buttons are used for initiating commands. In closed loop operation, the controller sends commands to the logic directly, with the interconnection results displayed on the MCDP. The weight associated with the present logic module is about $10 \mathrm{~kg}$.(33) Flight packaging should reduce this weight to $5 \mathrm{~kg}$.

To minimize weight, switching can occur only with power off (requiring all thrusters to be shut off during switching). Since cold thrusters (those not on prior to switching) require on the order of an hour to reach full power, the thrust distribution may be nonsymmetrical for a period of time. This effect must be considered by the TVC system.

\section{G. Propellant Storage}

The study of mercury propellant tankage concepts for an SEP system began in 1965.(34) Initially, positive expulsion metal bladders were used but were discarded because of fatigue failures and high pressurization requirements. Elastomeric bladders were chosen to avoid these problems.(35) The present tankage evolved frcm a design discussed in Ref. 36. A 23-cm diameter spherical tank was chosen to store about $82 \mathrm{~kg}$ of mercury. In contrast with the SERT II blow-down type pressurization that substantially increases the tank size, a pressurization scheme using a liquid in equilibrium with its vapor was chosen.

The vapor pressure of liquid Freon TF (113), in the temperature range of interest $\left(15\right.$ to $\left.50^{\circ} \mathrm{C}\right)$, provides suitable pressurization. The small liquid volume required is provided integrally with the propellant tank. This passive system eliminates regulators and high pressure as well as the pressurant tankage weight.

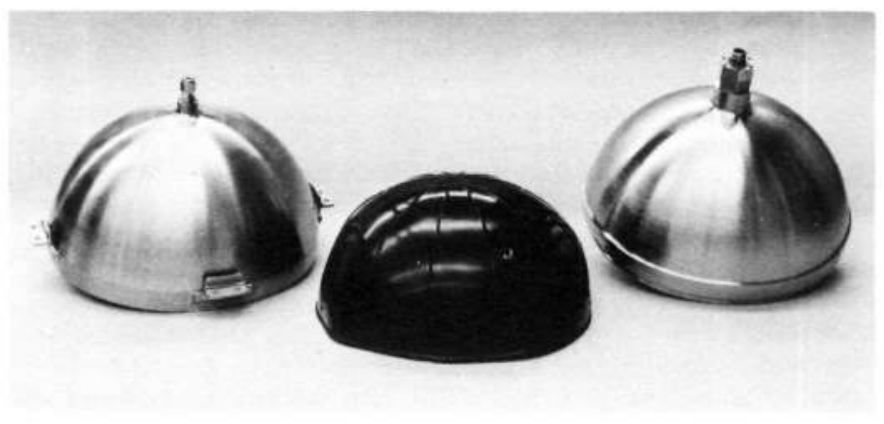

Figure 9. Mercury Propellant Tank Components (82-kg Capacity)

To minimize weight, Titanium $6 \mathrm{AL}-4 \mathrm{~V}$ is used. The compatibility with Freon and mercury at low temperature and pressure appears to be satisfactory. Fracture analysis is used to verify the $0.050-\mathrm{cm}$ wall thickness of the present design, shown in Fig. 9. Neoprene bladder composition, as well as bladder testing, has been discussed in Ref. 36. The tank, bladder, Freon and transducer weigh about $1.7 \mathrm{~kg}$. Including a valve and propellant lines, the propellant storage element weight is less than $3 \%$ of the propellant weight.

\section{H. Thrust Vector Control-Mechanism}

On spacecraft using SEP, the thrust vector control (TVC) element will provide normal attitude control and will correct for thrust vector misalignment and spacecraft CG changes due to propellant depletion. In general, three-axis control is required for this purpose. If out-of-plane forces can be accepted and control about all axes is not required simultaneously, two-axis gimballing may suffice. Many mechanization schemes have been proposed. These fall into two basic categories: (1) direct ion beam vectoring by electrostatic deflection, mechanical movement of the accelerator grid, or multiple-axis thruster gimballing; and (b) mechanical translation of the entire thruster array.

All methods in the first category are capable of providing control if two-axis beam vectoring, through a sufficiently large angle, is acceptable. Research on electrostatic and mechanical grid deflection is presently in progress at HAC under contract(37) and at NASA-LeRC. Further development is required before these concepts are ready for flight application. Two-axis gimballing does not appear to be difficult, although relatively large deflections (up to $30^{\circ}$ ) would be required for a multi-thruster system.

The principal limitation on two-axis gimballing, out-of-plane forces has resulted in the second category of TVC mechanization schemes. If gimballing is limited to one axis, the remaining two axes can be controlled by translation of the thruster array. Such a technique has been implemented in the present program. Previous studies have shown that 

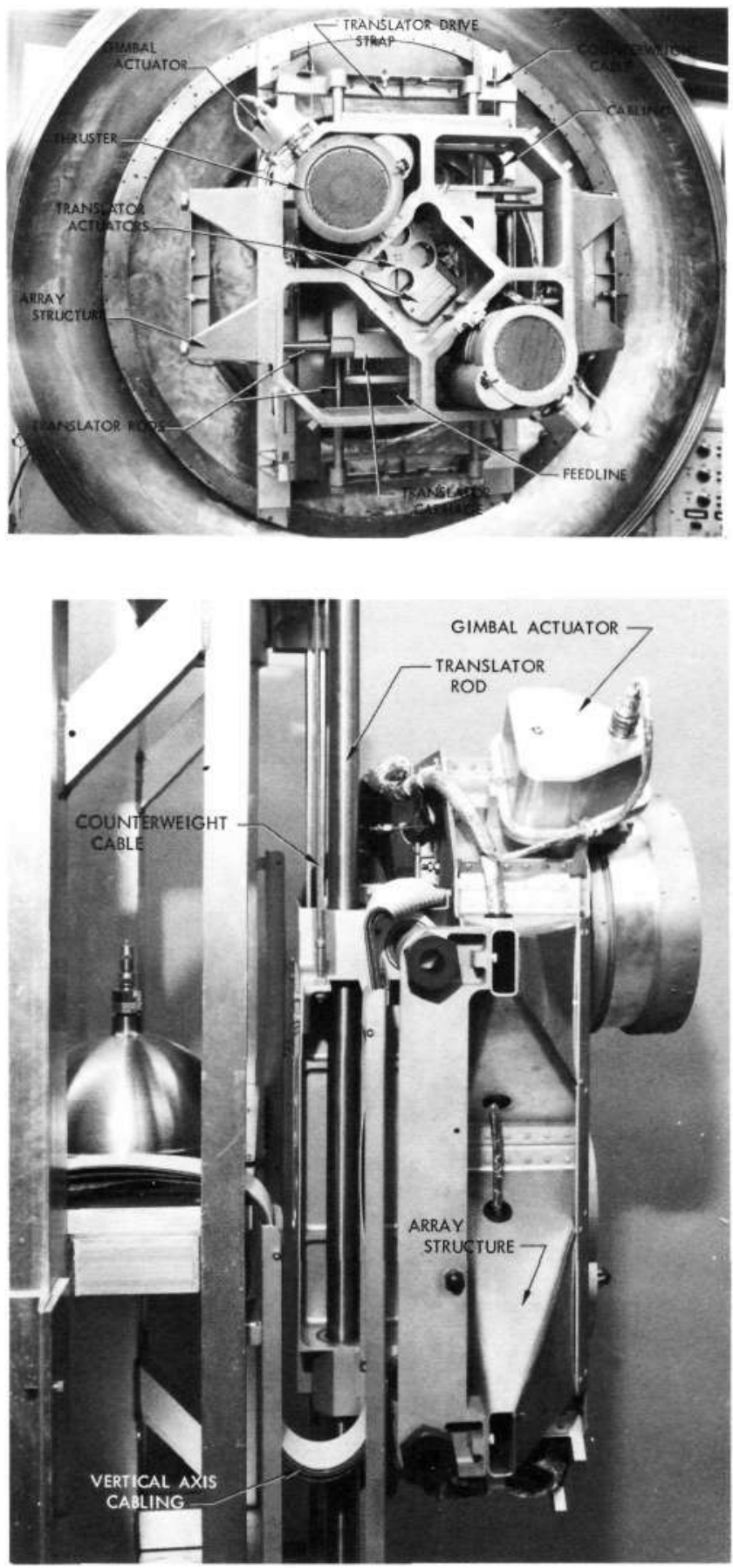

Figure 10. JPL Thrust Vector Çontrol Mechanism

this use of primary thrust for attitude control, accounting for the weight of the three axis mechanism, results in a lighter weight system than one using cold gas.(10)
The mechanism developed for SEPST is shown in Fig. 10. Translation and gimballing requirements are based on a Jupiter mission study* and are shown in Table 1 , which represent typical requirements. The life requirement places a significant constraint on actuator design. Stepper motors (typically used to drive the actuators) have life expectancies in the $10^{8}$ to $10^{9}$ step range. For normal limit cycle operation with a period of about one minute, a $10,000-\mathrm{hr}$ operation would require about $10^{6}$ corrections assuming a single-step deadband width. Including the capability to correct for a few large disturbances requiring full translation or gimballing and to perform ground testing, the life requirements are in the $10^{7}$ step range. However, the step requirements increase substantially if the limit cycle dead-band width is greater than one step. This increase places a requirement for near zero backlash on the mechanism design.

A near zero backlash system has been developed in the present program. This system is achieved by a combination of gears and inherently low backlash elements (split band and harmonic drive). All gears are used in a first stage. The low backlash element with a high reduction ratio reduces the gear backlash. Actuators, used in previous tests, have been redesigned to achieve lighter weight and a more flight-type design. Details of this design are presented in Ref. 38 .

The gimbal actuator is shown in Fig. 11. The stepper motor, through gears (50 to 1 reduction), drives a lead screw. A saddle nut on the lead screw drives the output sector by means of a split

Table 1. TVC requirements

\begin{tabular}{|c|c|c|}
\hline Parameter & $\begin{array}{l}\text { Translator } \\
\text { actuator }\end{array}$ & $\begin{array}{r}\text { Gimbal } \\
\text { actuator }\end{array}$ \\
\hline Output travel & $\pm 33 \mathrm{~cm}$ & \pm 10 degrees \\
\hline $\begin{array}{l}\text { Output torque } \\
\text { (at zero speed) }\end{array}$ & $40 \mathrm{Nm} *$ & $4.5 \mathrm{Nm}$ \\
\hline Slewing rate & $0.63 \mathrm{~cm} / \mathrm{sec}$ & $5 \mathrm{mrad} / \mathrm{sec}$ \\
\hline $\begin{array}{l}\text { Maximum } \\
\text { stepping rate }\end{array}$ & $100 \mathrm{step} / \mathrm{sec}$ & $\begin{array}{l}100 \text { step/ } \\
\text { sec }\end{array}$ \\
\hline Resolution & $\begin{array}{l}6.3 \times 10^{-3} \mathrm{~cm} / \\
\text { step }\end{array}$ & 20 arc $-\sec$ \\
\hline Backlash & $<0.5$ step & $<0.5$ step \\
\hline
\end{tabular}

\footnotetext{
*1975 Jupiter Flyby Mission Using a Solar Electric Propulsion Spacecraft," JPL Internal Report ASD 760-18, March 1968.
} 


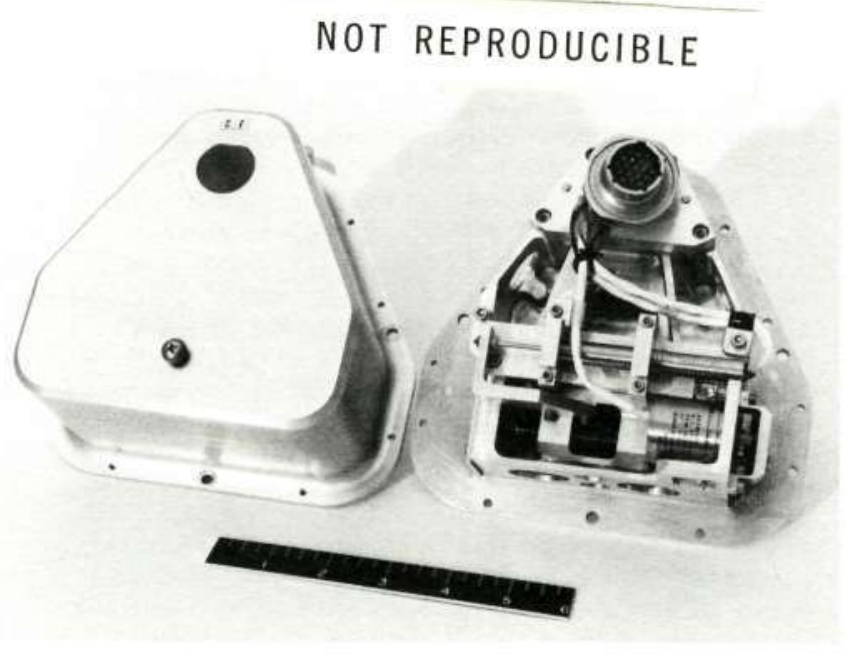

Figure 11. Gimbal Actuator

band ( 350 to 1 reduction). The output shaft, vacuum sealed with two O-rings, is clamped to the thruster gimbal shaft. An insulating spacer is used in the coupling to reduce heat transfer from the thruster. Spherical, self aligning bearings in pillow blocks are used for mounting to the thruster array. A torque of about $2.5 \mathrm{Nm}$ is produced for stepping rates up to about $100 \mathrm{step} / \mathrm{sec}$. The backlash between the stepper motor and output shaft has been found to be less than 2 step. This value will be reduced by minor adjustment of the lead screw-saddle nut backlash.

The translator actuator is shown in Fig. 12 . The stepper motor, through a gear, turns the harmonic drive unit that is attached to the output drum. The drum, sized to provide the required translation distance, drives a split berylliumcopper band to produce a relative motion between the actuator and a single axis of the array (see Fig. 10). Both translator actuators are mounted to a common carriage that also contains linear recirculating ball bearings for translator rod support. Each actuator produces a drive force in the band of $130 \mathrm{~N}$ at $100 \mathrm{step} / \mathrm{sec}$ and has a backlash of about 0.5 step.

The thruster array (see Fig. 10) structure, which moves in two axes, supports the gimbals and thrusters. It is constructed primarily of aluminum sheet with riveted joints. As shown, this array could support five thrusters, although fewer are presently used for simplicity. A third thruster will be added as a spare for system testing. For laboratory tests, the vertical axis is counterbalanced because the translator actuator in space is not required to lift the array weight. The lead counterweights fit within the vacuum header-array support structure (inside square tubing).

The thruster array dimensions are of interest in system design. The thruster plan form area $\left(A_{t}\right)$ exclusive of structure is (in $\mathrm{m}^{2}$ )

$$
A_{t}=\frac{\pi}{4}\left(n_{t}+n_{s}\right)\left(\gamma D_{b}\right)^{2}
$$

where $y$ is the ratio of maximum thruster diameter to beam diameter (typically 1.4). The overall array plan form area $\left(\mathrm{A}_{\mathrm{a}}\right)$ including structure and gimbal actuators can be expressed as

$$
A_{a}=\beta A_{t}=\frac{\beta \pi}{4}\left(n_{t}+n_{s}\right)\left(\gamma D_{b}\right)^{2}
$$

where $\beta$ is the ratio of array to thruster area. A value of $\beta$ of 2.0 is typical of most packaging concepts. Thus, the array area can be represented approximately by

$$
A_{a}=3\left(n_{t}+n_{s}\right) D_{b}^{2}
$$

Assuming the array is formed relatively symmetrically, a characteristic dimension of the array $\left(\mathrm{L}_{\mathrm{a}}\right)$ is $\left(\mathrm{A}_{\mathrm{a}}\right)^{1 / 2}$ or

$$
L_{a}=1.7 D_{b}\left(n_{t}+n_{s}\right)^{1 / 2}
$$

which is equivalent to the dimensions of a square. The maximum dimension could thus be expected to be approximately

$$
\begin{aligned}
L_{a, \max } & =(2)^{1 / 2} L_{a} \\
& =2.4 D_{b}\left(n_{t}+n_{s}\right)^{1 / 2}
\end{aligned}
$$

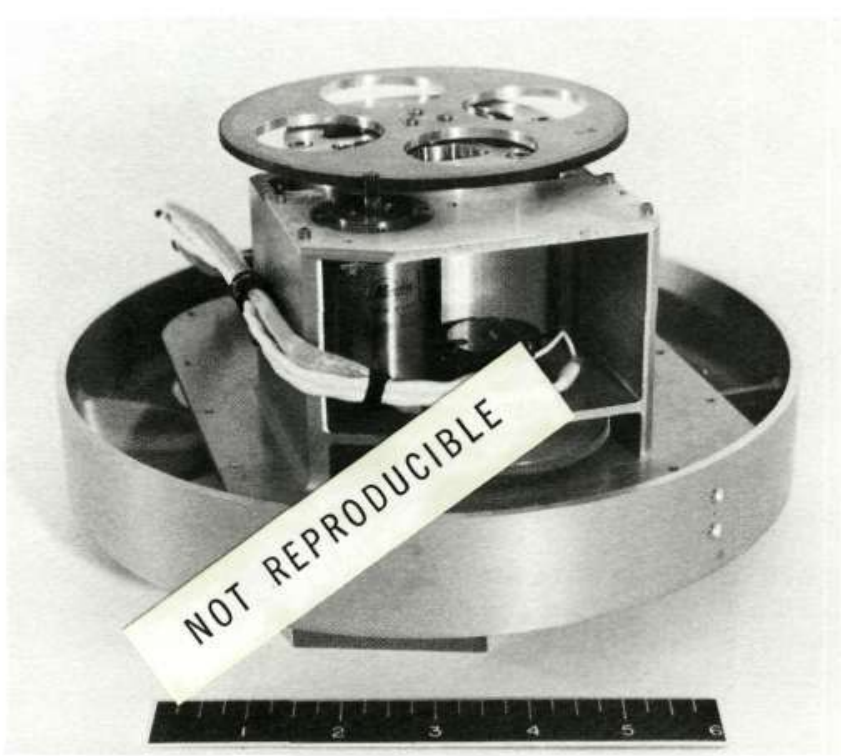

Figure 12. Translator Actuator 
In terms of power, Eq. (18) becomes

$$
L_{a}=\frac{1.1 \times 10^{3}}{I_{s p}}\left[\frac{\eta_{m} \eta_{t} \eta_{c}\left(n_{t}+n_{s}\right){ }^{\mathscr{P}}}{n_{t}}\right]^{1 / 2}
$$

Although only approximate, Eq. (20) shows that array dimensions are relatively independent of $n_{t}$, vary directly with $\left(\mathcal{P}_{c}\right)^{1 / 2}$, and vary inversely with Isp.

The thruster array mass, including gimbal bearings, is expected to be approximately half the thruster mass. Since the actual value depends entirely on the specific design, this structure mass $\left(\mathrm{M}_{\mathrm{m}}\right)$ will be assumed to be, for estimating purposes,

$$
\mathrm{M}_{\mathrm{m}}=0.5 \mathrm{M}_{\mathrm{t}}
$$

The translation distance is determined by the requirement of maintaining control with an outboard thruster operating alone. It will be assumed that the most outboard thruster center must be translated half a thruster diameter past center. The translation distance in each direction $c$ an be written

$$
L_{d}=\left(\frac{n t r}{2}-1\right)\left(\gamma D_{b}+\sigma\right)+\left(\gamma D_{b}+\frac{\sigma}{2}\right)
$$

where $\mathrm{n}_{\mathrm{tr}}$ is the rumber of thrusters in the longest row, and $\sigma$ is the edge to edge thruster spacing. The thruster spacing can be expected to depend on gimbal actuator design and thruster layout. The total translator length is the sum of $2 \mathrm{~L}_{a}$ and the translator shaft bearing spacing $\left(\mathrm{L}_{b}\right)$. The bearing spacing, which depends on actuator design and shaft stiffness, can be expected to be about equal to $I_{a}$. Therefore, the total translator shaft length $\left(L_{\mathbf{r}}\right)$ is

$$
L_{r}=3.0 L_{a}=1.50\left[n_{t r} \gamma D_{b}+\sigma\left(n_{t r}-1\right)\right]
$$

The translator shaft mass can now be estimated. It will be assumed that the shafts are tubes with diameters of $1 / 50 \mathrm{~L}_{\mathbf{r}}$, with wall thickness of about $4 \times 10^{-3} \mathrm{~m}$, and density $\rho_{\mathrm{r}}$. The shaft mass is approximately

$$
M_{r}=2.5 \times 10^{-4} \rho_{r} L_{r}^{2}
$$

substituting for $\mathrm{L}_{r}$

$$
M_{r}=5.6 \times 10^{-4} \rho_{r}\left[n_{t r} \gamma D_{b}+\sigma\left(n_{t r}-1\right)\right]^{2}
$$

and using Eq. (10)

$$
\begin{aligned}
& M_{r}= \\
& \left.5.6 \times 10^{-4} \rho_{r}\left\{n_{t r} \gamma\left[\frac{6.30 \times 10^{2}}{I_{s p}}\left(\frac{\eta_{m} \eta_{t} \eta_{c} P_{c}}{n_{t}}\right)^{1 / 2}\right]+\sigma\left(n_{t r}-1\right)\right\}\right\}^{2}
\end{aligned}
$$

Translator shaft supports at the mounting structure and spacecraft interfaces weigh about $1 \mathrm{~kg}$ per translation axis, while translator shaft bearings weigh about $1 \mathrm{~kg}$ per axis.

To meet the requirement for flexible highvoltage cabling across the moving interfaces with proven spacecraft-compatible materials, Teflon (TFE) insulated ribbon cable (Gore and Associates, Inc.) was selected. A total of four cables are used; two for the thruster and two for the actuators. The thruster high-current (up to $10 \mathrm{~A}$, floating at $+2 \mathrm{kV}$ ) requirements (arc, common, and cathode heater) are met using four 19-strand 20-Awg conductors in parallel. The four conductors are insulated together. Nine of these sets are bonded into ribbon form with another layer of Teflon. The remaining nine-thruster low-current requirements (including potentials of $+2 \mathrm{kV},-1 \mathrm{kV}$, and ground) are met with 19-strand 20-Awg single conductors bonded in ribbon form. The actuators require twisted shielded pairs and triads for minimum EMI. A cable (each of pairs and triads, using braided shielding and 28-Awg conductors) is used. Each ribbon is about $6 \mathrm{~cm}$ wide.

The four ribbon cables are stacked and formed into an open loop. Beginning at an attachment point on the array, the first loop lays in a horizontal tray attached to the carriage. Thus, the loop "rolls" in this tray as the array moves relative to the carriage. The cables are then bent $90^{\circ}$ and twisted $90^{\circ}$ to form a second loop along the vertical axis. Supported by trays on the carriage and mounting structure, this loop crosses the second axis. This design results in a total loop ( 4 cables) rolling force of about 5-6 Newtons. On the carriage, the actuator cables are split for operation of the translator actuators. On the array, all of the cables are split and distributed as required. The combined weight of the four ribbons is about $4 \mathrm{~kg}(1.12 \mathrm{~kg} / \mathrm{m})$.

The propellant feedline crosses the translator in a rolling loop design similar to that for the cabling. Fully hardened $0.157-\mathrm{cm}$ diameter stainless steel tubing is first formed into a $1.9-\mathrm{cm}$ diameter spring type coil. This coil is formed into an open loop and is supported in small hemispherical trays on the array, carriage, and mount- 
ing structure. As with the cabling, the feedline loop rolls without appreciable force. Separate coils ( 3 meters each) are used for each axis with a junction on the carriage. Single lines are run to each thruster from the distribution point on the array.

Including the cabling, feedline, and bearing friction, a force of about 10 Newtons is required to drive the horizontal axis. Due to friction between the counterweights and the structure and the friction in the counterweight pulleys, about 30 Newtons is required to drive the vertical axis. These forces are easily provided by the translator actuators.

Vacuum testing of the mechanism and thrusters, as shown in Fig. 10, for a total of about 150 hr has been accomplished. The only problem observed was in the gimbal actuator. Over lubrication of the high-tolerance lead screw initially caused the actuator to stall. Cleaning and relubrication fixed this problem. More than $2 \times 10^{7}$ steps have been logged on two actuators in vacuum. Both translators were operated problem free for this 150-hr period, accumulating about $2000 \mathrm{com}-$ plete cycles on each axis. This operation amounts to about $4 \times 10^{7}$ steps per actuator. The gimbal and translator actuators have all completed more than $10^{7}$ steps in air prior to vacuum testing. The flexible cabling and feedline show no visible signs of wear or fatigue. Original cabling and feedlines have been used throughout breadboard, air, and vacuum tests for five months. The motion of the mechanism did not significantly affect thruster operation, although the accelerator current varied periodically $( \pm 5 \%)$ during translation. This variation is attributed to the change of vacuum chamber wall-thruster distance. Future tests are intended to determine stepper motor, cabling, and feedline life.

\section{Thrust Vector Control - Electronics}

The TVC mechanism has produced a new problem for the spacecraft attitude control system designer. Movement of the relatively large mass of the mechanism results in a spacecraft angular displacement. A translator motion, intended to correct an attitude error, produces an additional angular error in the same direction. Without proper compensation, a simple control loop would be unstable. This subtle fact was apparently recognized by Mankovitz of JPL during the Jupiter mission study (previously cited) but not explicitly stated. This instability was later noted by Barbera of NAR. (1)

The control scheme adopted to solve this problem is a modified form of that proposed by Mankovitz.(39) The control loop is indicated in Fig. 13. The stabilizing network basically reduces the amount of error signal seen by the forward loop. The compensation network includes both translator position and velocity.

The closed loop control electronics have been breadboarded at this time. Tests on a single-axis

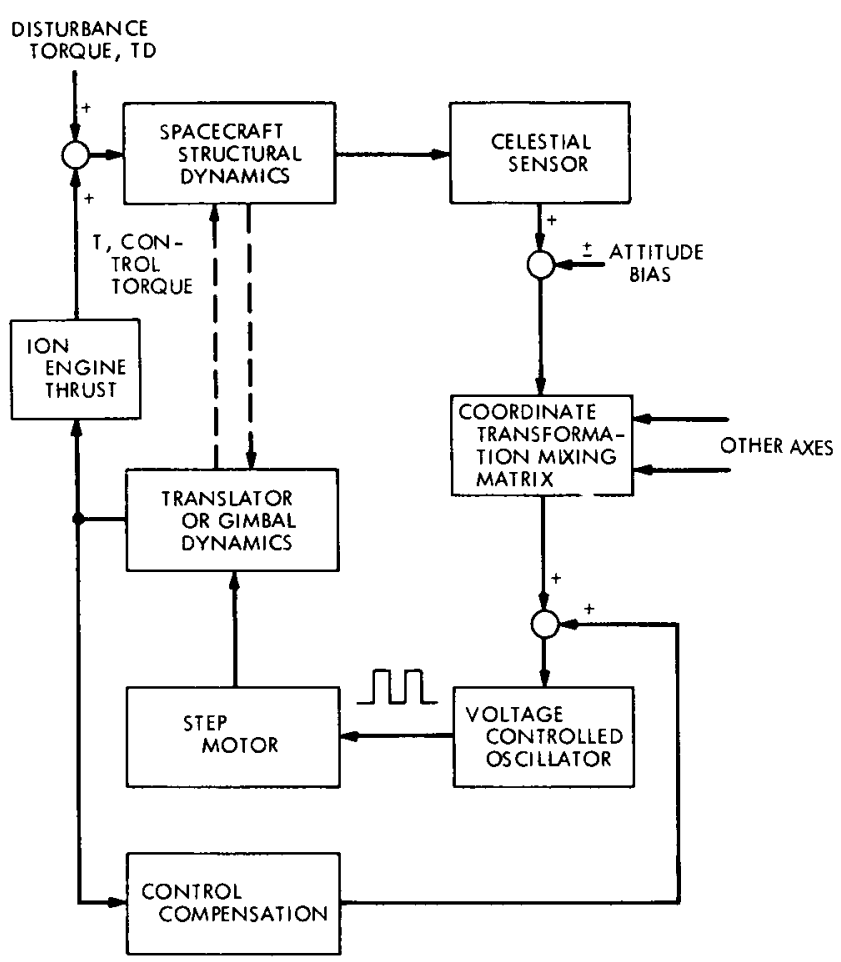

Figure 13. Basic Translator Axis or Gimbal Axis Control Loop

loop, using an analog simulation of spacecraft dynamics, produced results quite similar to those determined analytically.(40) The results are indicated in Fig. 14. The similarity of the convergence of the phase plane characteristics is striking. The mass of these electronics, packaged for flight, is estimated to be $3.7 \mathrm{~kg}$.

\section{J . Controller}

The logic functions, relating to the propulsion system, are expected to be included in the spacecraft central computer and sequencer (CC\&S). Such units have been developed for Mariner and Surveyor spacecraft. However, a detailed study must be performed to determine the compatibility of the SEP requirements with present CC\&S units. As indicated in Fig. 1, the current program refers to the propulsion system portion of the CC\&S as the controller.

The controller for the present program consists of a small commercial computer and an operator's panel for manual control. The ground station is simulated by the teletype that communicates with the computer. The input/output logic is designed to provide the necessary interface between the computer and the individual components of the thrust subsystem.

The principal functions considered for incorporation into the controller are thruster startup 

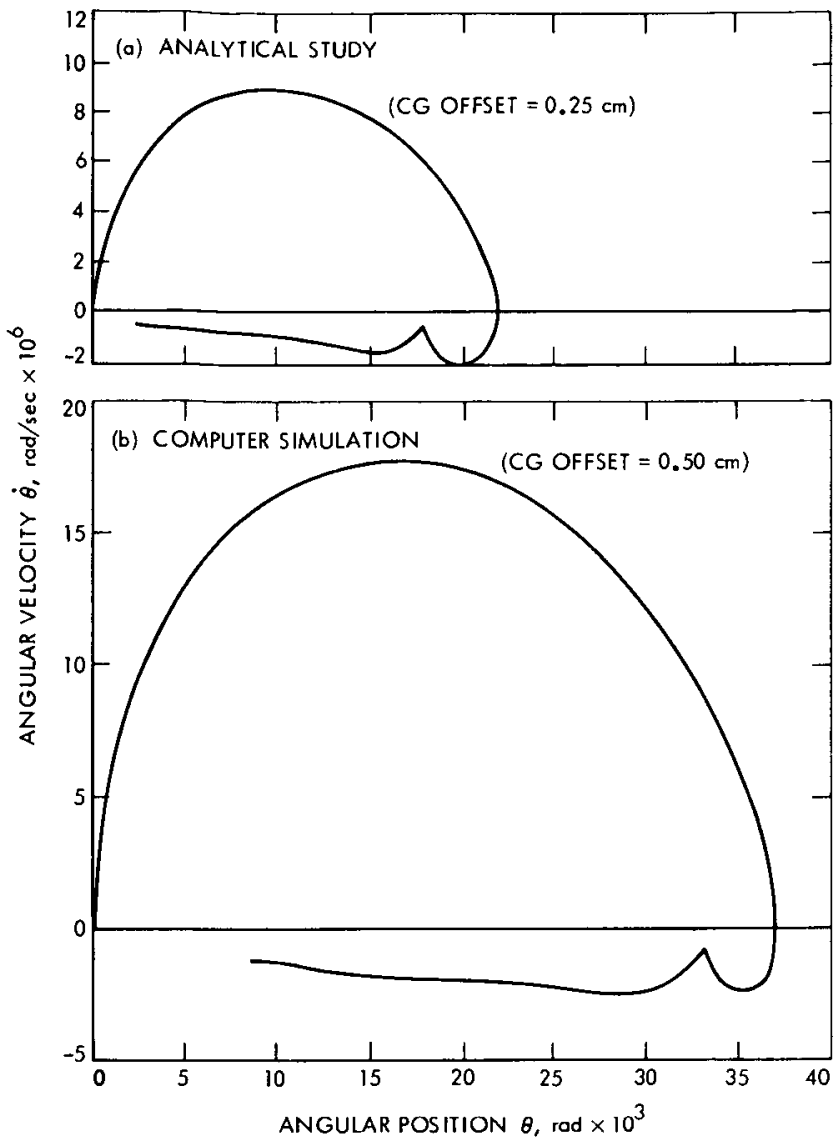

Figure 14. Translator Control Loop Phase Plane Response: (a) Analytical and (b) Analog Simulation

and shutdown, power conditioner function monitoring, solar array MPPD interrogation, power programming, failure detection, and switching instructions. Under normal circumstances, when all subsystems function as required, the controller relays the ground station commands to the thrust subsystem and monitors the performance of selected critical elements.

In case of failure or out-of-limit operation, the controller is required to take over control of the spacecraft until the next contact with the ground station and to initiate all of the corrective actions required to maximize the subsystem performance. All the functional subroutines are executed with software to obtain the flexibility that is necessary during these initial phases of development so that the methods of system control, control interactions, and the program complexity can be evaluated and optimized. It is expected that the majority of the above subroutines will ultimately be performed by electronic hardware, thus considerably reducing the size of the computer memory. No parametric trade-off studies of the ultimate size of the flight-type controller have been generated thus far.

\section{SEP System - Spacecraft Interactions}

Element development has progressed to the extent that greater attention must now be given to element mutual interactions and element-spacecraft interactions. These interactions are of such significance that final element designs cannot be established without a realistic total system integration. Four general categories of interactions exist: electrical/electromagnetic, stability, thermal, and mechanical. The first of these is probably the most difficult to design for or evaluate. The stability and thermal interactions are somewhat more apparent and can be treated analytically, while the mechanical interactions can be evaluated rather directly in design.

Within the electrical interaction category are the conducted and radiated EMI, disturbance of the common input power buss, high-voltage isolation (up to $2 \mathrm{kV}$ ), the cabling mass-voltage drop trade-off, and spacecraft potential dependence on ion beam neutralization. Due to the basic nature of the SEP system, in terms of high-power inverter operation and thruster accelerator-screen grid arc transients, normal spacecraft electronic subsystems will probably require additional filtering protection and careful grounding techniques. This requirement should not be a major difficulty since power conditioning units with similar integrated circuit electronics have demonstrated reliable operation in this high-noise environment after suitable filtering. (41) However, such requirements should be established at the outset of spacecraft system development.

The two most important system stability problems occur between the thruster and power conditioner and between the TVC and the spacecraft. Both of these involve marginal or neutral stability. 'Thruster control and stability have been discussed previously for the oxide (9) and hollow cathode (42) thrusters. The thruster (with either cathode) when operated with conventional control loops $(43,44)$ is stable for a limited range of propellant utilization efficiency; typically above $70 \%$. Without special compensation, the main vaporizer control loop will increase the propellant flowrate to an excessive level if the utilization efficiency drops below the stable operating limit. With the hollow cathode system the problem is accentuated. The discharge voltage is primarily adjusted by controlling the flowrate through the hollow cathode. However, the discharge voltage also depends on the main flow. The vaporizer response time, particularly in cooling, is slow and a large increase in the main flow can swamp out the effect of the hollow cathode flow. This action causes the discharge voltage to drop rapidly, forcing the propellant utilization down. For large enough steps in beam current demand or during the startup stabilization period, the thruster main flowrate will "run-away." Sensing of this condition can be used to shut off the main vaporizer and drive the utilization efficiency back within the stable range. A circuit to prevent the run-away condition has been used successfully. (45) 
Table 2. SEPST III weight summary

\begin{tabular}{|c|c|c|c|}
\hline & \multirow{2}{*}{$\begin{array}{l}\text { Present, } \mathrm{kg} \\
\left(\begin{array}{c}3 \text { thrusters } \\
2 \text { PC units }\end{array}\right)\end{array}$} & \multicolumn{2}{|c|}{ Future, kg } \\
\hline & & $\left(\begin{array}{c}3 \text { thru sters } \\
2 \text { PC units }\end{array}\right)$ & $\left(\begin{array}{cc}5 & \text { thrusters } \\
4 & P C \text { units }\end{array}\right)$ \\
\hline Thruster $(20 \mathrm{~cm})$ & 15.3 & 13.5 & 21.5 \\
\hline TVC actuators ${ }^{\dagger}$ & 8.8 & 7.4 & 11.8 \\
\hline TVC thruster array and translator & 55.0 & 22.0 & 22.0 \\
\hline Power conditioner $(2.75 \mathrm{~kW})$ & 36.0 & 29.0 & 58.0 \\
\hline Controller $(\mathrm{CC} \& \mathrm{~S})^{* *}$ & $5.2 *$ & 5.2 & 5.2 \\
\hline Switching Logic ${ }^{\dagger}$ & 3.7 & 3.0 & 3.0 \\
\hline Switches $†$ & 5.0 & 4.0 & 6.0 \\
\hline Flexible cabling & 5.7 & 5.0 & 7.0 \\
\hline Flexible feedlines & 1.0 & 1.0 & 1.0 \\
\hline Caging for launch $†$ & $3.0^{* *}$ & 3.0 & 3.0 \\
\hline Miscellaneous cabling and fittings $\dagger$ & $2.0^{*}$ & 2.0 & 2.0 \\
\hline Total & 140.7 & 94.1 & 140.5 \\
\hline $\begin{array}{l}\text { *Estimates for flight hardware. } \\
\text { **Half of total CC\&S. } \\
{ }^{\dagger} \text { Fixed mass. }\end{array}$ & & & \\
\hline
\end{tabular}

The TVC-spacecraft stability problem has been analyzed extensively. $(39,40,46) *$ In this case, the motion of the TVC mechanism mass, when driven in a direction to correct a spacecraft attitude error, introduces an additional angular error in the same direction as the original error. This positive feedback effect is compensated for by reducing the error signal sent to the forward portion of the control loop (see Fig. 13). This technique works for a limited range of control loop gain. In addition, for a given loop gain, stability is achieved within a limited range of total thrust level. The effect of a time varying thrust level, due to thruster random arcing, does not appear to affect stability. (46)

Thermal interactions are expected to occur principally in the thruster-actuator, thrusterspacecraft, propellant storage-spacecraft, and the power conditioner-space/spacecraft areas. These interactions have been considered in element design.

Mechanical interactions include solar array, TVC mechanism, and power conditioner mounting, ion beam angular distribution, propellant storage concentrated loads, TVC mechanism launch caging, flexible cabling, and flexible propellant feed- lines. Although many of these are straightforward design problems, the ion beam angular distribution and flexible cabling and feedline problems require design information (the present program provides cabling and feedline information). Ion beam divergence, particularly at low $I_{s p}$, has not been fully investigated.

The SEP system operation is further complicated by the solar power variation (15) inherent in traveling toward or away from the sun. This power variation can be as great as 10 to 1 . Ion thruster efficiency becomes unacceptably low for throttling of more than 3 to 1 in power, requiring multiple thrusters to be used to accomplish solar power matching. However, an amount of redundancy is introduced through the fact that thrusters, shut off during the throttling process, become available spares. As noted previously, the TVC stability problem must consider the power or thrust variation.

\section{System Mass Summary}

The application of SEP depends to a large degree upon satisfying weight constraints. Since mission calculations are presently based on a total specific mass of $30 \mathrm{~kg} / \mathrm{kW}$, it is important to

\footnotetext{
"Sahinkaya, Y. E., "Stability Analysis for the Thrust Vector Control System of a Solar Powered Electrically Propelled Space Vehicle," JPL Engineering Memorandum 344-264-YES, March 1970.
} 
assess this number realistically: The solar array specific weight is assumed to be independent of power level. Accounting for an $18 \%$ degradation factor, a $15 \mathrm{~kg} / \mathrm{kW}$ solar array becomes $18.3 \mathrm{~kg} / \mathrm{kW}$.

The thrust subsystem element mass breakdown for the present and a similar future system is shown in Table 2. The "future" column values correspond to the estimates of flight-type designs as discussed previously. These masses provide a reasonable reference point from which extrapolations can be made. The TVC electronics, MPPD, and auxiliary power elements are ordinarily, included on a spacecraft. These should not be charged against the propulsion system and are not included in Table 2 . The propellant storage is accounted for in the propellant mass. The mass of many elements is not expected to depend greatly on power or $I_{s p}$. Equations were presented previously for the mass of the other elements. The equations and fixed masses were used to derive Fig. 15, using the following assumptions:
a. Propellant utilization efficiency, $\eta_{\mathrm{m}}=0.9$

b. Power conditioner efficiency, $\eta_{c}=0.90$

c. Spare thrusters, $n_{s}=1$

d. Number of PC units, $n_{c}=n_{t}$

e. Spare PC units, $n_{p}=0$

f. Translator rod material: beryllium

g. Two-axis translation

Figure 15 indicates that the $30 \mathrm{~kg} / \mathrm{kW}$ specific mass used in mission calculations is a reasonable average for all $I_{s p}$ values used. However, at lowpower levels, the specific mass is expected to be much higher, while at high-power levels, less than $30 \mathrm{~kg} / \mathrm{kW}$ is expected. The specific mass is also inversely dependent upon $I_{s p}$.

The incorporation of the variation in specific mass illustrated in Fig. 15 in mission calculations should have two basic effects. First, the mass variation with power would result in relatively higher optimum power levels. Second, the mass variation with $I_{s p}$ would produce somewhat higher optimum $I_{s p}$ values. Thus, present mission calculations optimizing above approximately $12 \mathrm{~kW}$ are conservative; those below $12 \mathrm{~kW}$ are somewhat optimistic.
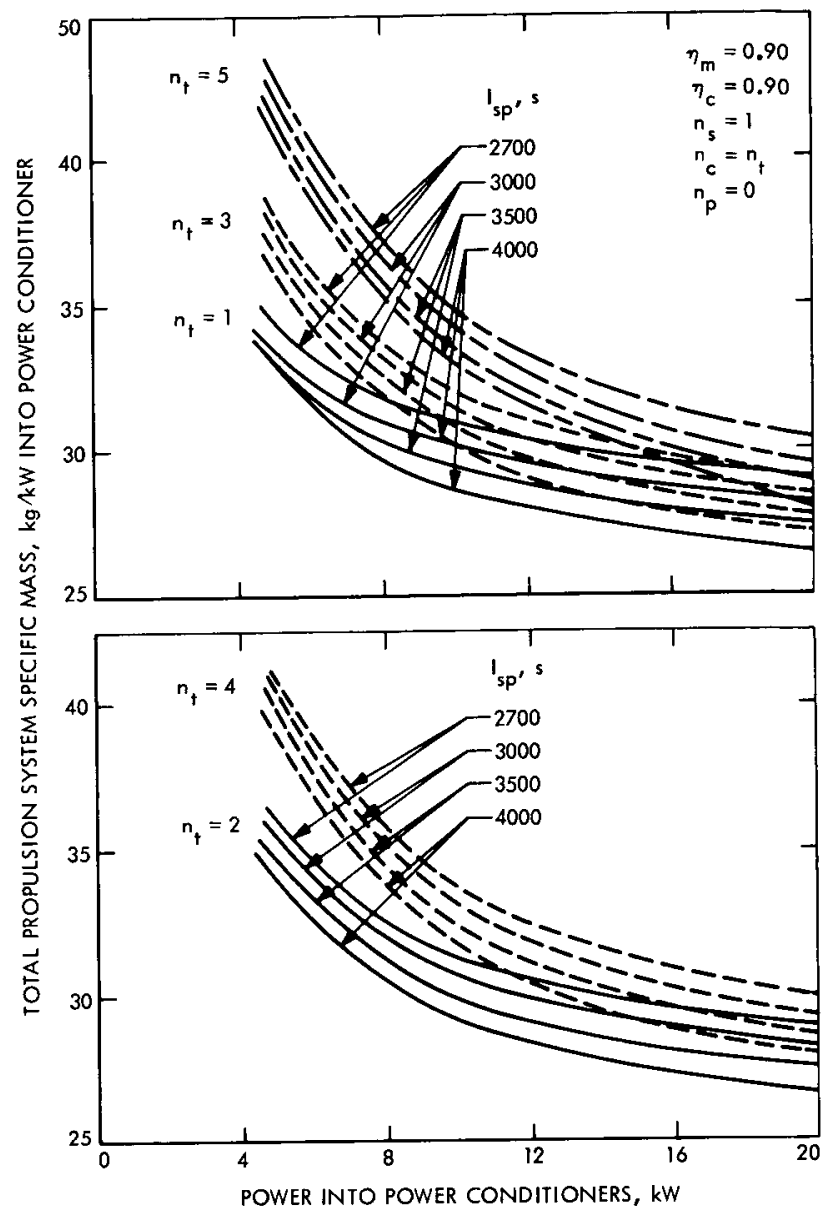

Figure 15. T'otal Propulsion System Specific Mass as a Function of Power Into the Power Conditioners

\section{Conclusions}

The elements required for building a solar electric propulsion system are on hand. With few exceptions (MPPD and controller), the flight prototype units could be constructed directly, using current technology, within the required weight and efficiency limits. After proceeding to the present level of system testing (i.e., PC-thruster integration, TVC mechanization, and closed loop attitude control demonstration), no fundamental problems are apparent. The expected problems of EMI, environmental qualification, and integration of the complex electronics elements, should not be substantially different from non-SEP spacecraft.

System testing in the SEPST program will continue to investigate element interactions, propulsion system/spacecraft compatibility, and capability of meeting life requirements. Based on the results of all system and component testing to date, it would appear that, for all practical purposes, SEP technology is ready. 


\section{$\underline{\text { References }}$}

l'Solar Electric Propulsion Asteroid Belt Mission Study," Final Report on JPL Contract 952566, North American Rockwell Document SD-70-21, January 1970.

2"Study of a Solar Electric Multi-Mission Spacecraft," Final Report on JPI Contract 952394, TRW, Inc., Document 09451-6001-RO-02, January 1970 .

${ }^{3}$ Bartz, D. R., and Horsewood, J. L., "Characteristics, Capabilities, and Costs of SolarElectric Spacecraft for Planetary Missions, " AIAA Paper 69-1103, AIAA Sixth Annual Meeting and Technical Display, October 1969.

4Wrobel, J. R., and Kerrisk, D. J., "Early Exploration of the Asteroids Region by Solar Powered Electrically Propelled Spacecraft," Paper XA. 4 from Joint National Meeting of the American Astronautics Society (15th Annual) and the Operations Research Society (35th National), June 1969.

${ }^{5}$ Kerrisk, D. J., "Implications of Electric Propulsion Systems for Spacecraft Designs," paper presented at the ASME Space Technology and Heat Transfer Conference, June 1970.

${ }^{6}$ Stearns, J. W., and Kerrisk, D. J., "SolarPowered Electric Propulsion Systems - Engineering and Applications," AIAA Paper 66-576, AIAA Second Propulsion Joint Specialists Conference, Colorado Springs, Colo., June 1966.

7Kerrisk, D. J., and Kaufman, H. R., "Electric Propulsion Systems for Primary Spacecraft Propulsion," AIAA Paper 67-424, AIAA Third Propulsion Joint Specialists Conference, July 1967.

8Kerrisk, D. J., and Bartz, D. R., "Primary Electric Propulsion Systems Technology and Applications," Astronaut. Aeronaut., Vol. 6, No. 6, June 1968.

${ }^{9}$ Masek, T. D., and Pawlik, E. V., "Thrust System Technology for Solar Electric Propulsion," AIAA Paper 68-541, AIAA Fourth Propulsion Joint Specialist Conference, June 1968.

10Reader, P. D., and Mankovitz, R. J., "Attitude Control of an Electrically Propelled Spacecraft Utilizing the Primary Thrust System," paper presented at the ASME Annual Aviation and Space Conference, June 1968.

11"Rollup Subsolar Array," Quarterly Report No. 4 under JPL Contract 952314, General Electric Report GE-SSO-70SD4225, March 1970.

12Herron, B. G. , "High-Voltage Solar Arrays with Integral Power Conditioning," AIAA Paper 70-1158, AIAA Eighth Electric Propulsion Conference, August 1970.
${ }^{13}$ Oman, H. , "High-Voltage Solar Array for Ion Engines," AIAA Paper 70-1138, AIAA Eighth Electric Propulsion Conference, August 1970.

${ }^{14}$ Bayless, J. R., Todd, G. T., Ward, J. W., and Knauier, W., "Feasibility of High-Voltage Solar Arrays," AIAA Paper 70-1137, AIAA Eighth Electric Propulsion Conference, August 1970.

$15_{\text {Sandstron, J. D., "Electrical Characteristics }}$ of Silicone Solar Cells as a Function of Cell Temperature and Solar Intensity," paper presented at the Third Intersociety Energy Conversion Engineering Conference, Boulder, Colo., August 12-16, 1968 .

16Macie, T. W., Pawlik, E. V., Ferrera, J. D., and Costogue, E. N., "Solar-Electric Propulsion System Evaluation," AIAA Paper 69-498, AIAA Fifth Propulsion Joint Specialist Conference, June 9-13, 1969.

${ }^{17}$ Rawlin, V. K., and Kerslake, W. R., "Durability of the SERT II Hollow Cathode and Future Applications at Higher Emission Levels," AIAA Paper 69-304, AIAA Seventh Electric Propulsion Conference, March 1969.

${ }^{18}$ Hyman, J., Bayless, J. R., Schnelker, D. E., and Ward, J. W., "Liquid Mercury Cathode Thruster Systems," AIAA Paper 70-646, AIAA Sixth Propulsion Joint Specialist Conference, June 1970 .

19 Banks, B. A., and Bechtel, R. T., "1000-Hour Endurance Test of a Glass-Coated Accelerator Grid on a 15-cm-Diameter Kaufman Thruster," NASA TN D-5891, National Aeronautics and Space Administration, Washington, D. C., July 1970.

20 King, H. G., and Poeschel, R. L., "A 30-cmDiameter, Low-Specific Impulse, Hollow Cathode Mercury Thruster," AIAA Paper 70-1099, AIAA Eighth Electric Propulsion Conference, August 1970 .

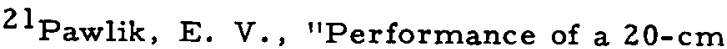
Hollow Cathode Ion Thruster," proposed JPL Technical Report.

${ }^{22}$ Pawlik, E. V., "Neutralization of a Movable Ion Thruster Exhaust Beam," in Supporting $\mathrm{Re}-$ search and Advanced Development, SPS 37-58, Vol. III, Jet Propulsion Labor atory, Pasadena, Calif., August 1969.

23"Cesium Feed Systems Electrical Isolation," Final Report on JPL Contract NAS 7-502, Electro-Optical Systems, Inc., March 1968.

${ }^{24}$ Masek, T. D., "Evaluation of the SE-20C Thruster, Design," in Supporting Research and Advanced Development, SPS 37-51, Vol. III, Jet Propulsion Laboratory, Pasadena, Calif. , June 1968 . 
25 Masek, T. D., "Sizing a Solar Electric Thrust Subsystem," Technical Report 32-1504, Jet Propulsion Laboratory, Pasadena, Calif., Oct. 15, 1970.

${ }^{26}$ Muldoon, W. J., Garth, D. R., and Benson, G. C. "Functional and Physical Design of a Flight Prototype Ion Engine Power Conditioner," ASME Paper 70-AV/SPT-38, ASME Space Technology and Heat Transfer Conference, June 1970.

${ }^{27}$ Cronin, D., Goldin, D., and Biess, J., "Power Conditioning Suitable for High-Performance Electric Spacecraft," AIAA Paper 69-240, ALAA Seventh Electric Propulsion Conference, March 1969.

${ }^{28}$ Schwarz, F. C., "A Governing Electronic Mechanism for Ion Propulsion Engines," AIAA Paper 70-1157, AIAA Eighth Electric Propulsion Conference, August 1970.

29"Development and Test of an Ion Engine System Employing Modular Power Conditioning," Final Report on JPL Contract 951144, Hughes Aircraft Company Document SSD60374R, September 1966.

${ }^{30}$ Pawlik, E. G., Costogue, E. N., and Schaefer, W. C. , "Operation of a Lightweight Power Conditioner with a Hollow Cathode Ion Thruster," AIAA Paper 70-648, AIAA Sixth Propulsion Joint Specialist Conference, June 1970.

${ }^{31}$ Macie, T. W., and Masek, T. D., "Power Conditioner Evaluation-Circuit Problems and Cures SEPST III, BB-1," in Supporting Research and Development, SPS 37-62, Vol. III, J et Propulsion Laboratory, Pasadena, Calif., April 1970.

32 Macie, T. W., "Solid State Switching for Solar Electric Propulsion," proposed JPL Technical Report.

33Costogue, E. N., "Electric Propulsion Power Conditioning," in Supporting Research and Development, SPS 37-61, Vol. III, Jet Propulsion Laboratory, Pasadena, Calif., February 1970.

${ }^{34}$ Kerrisk, D. J., and Masek, T. D., "A ZeroGravity Mercury Propellant Feed System, "AIAA Paper 66-250, AIAA Fifth Electric Propulsion Specialists Conference, March 7-9, 1966.

35 Masek, T. D., and Womack, J. R., "Experimental Studies with a Mercury Bombardment Ion Engine System," ALAA Paper 67-698, AIAA Fifth Electric Propulsion and Plasmadynamics Conference, September 1967 (also, JPL TR 32-1280).

36womack, J. R., "Design and Evaluation of Propellant Tankage for SEPST Program," in Sup- porting Research and Development, SPS 37-58, Vol. III, Jet Propulsion Laboratory, Pasadena, Calif., August 1969.

37'Thrust Vectoring Systems for Mercury Ion Thrusters," Monthly Report No. 2 under NASALeRC Contract NAS 3-14058, Hughes Research Laboratories, June 1970.

38Perkins, G. S., Johnson, K. G., Ferrera, J. D., and Masek, T. D., "A Mechanism for ThreeAxis Control of an Ion Thruster Array," AIAA Paper 70-1156, AIAA Eighth Electric Propulsion Conference, August 1970.

${ }^{39}$ Crawford, W. E., and Fleischer, G. E., "Solar Electric Spacecraft Thrust Vector Control Mechanization," in Supporting Research and Development, SPS 37-62, Vol. III, Jet Propulsion Laboratory, Pasadena, Calif., April 1970.

${ }^{40}$ Crawford, W. E., "Solar Electric Propulsion System Technology Project Thrust Vector Control Electronics," in Supporting Research and Development, SPS 37-64, Vol. III, Jet Propulsion Laboratory, Pasadena, Calif., August 1970.

4lMuldoon, W. J., Garth, D. R., and Benson, G. C., "Application of Integrated Circuits in Ion Engine Power Conditioning," AIAA Paper 70-649, AIAA Sixth Propulsion Joint Specialist Conference, June 1970.

42Pawlik, E. V., and Masek, T. D., "ClosedLoop Operation of a Hollow Cathode Ion Thruster," in Supporting Research and Development, SPS 37-60, Vol. III, Jet Propulsion Laboratory, Pasadena, Calif., December 1969.

43 Bechtel, R. T., "Performance and Control of a 30-cm Diameter Low Impulse Kaufman Thruster," AIAA Paper 69-238, AIAA Seventh Electric Propulsion Conference, March 1969.

${ }^{44}$ Muller, P. A., and Pawlik, E. V., "Control Analysis of an Ion Thruster with Programmed Thrust," AIAA Paper 69-239, AIAA Seventh Electric Propulsion Conference, March 1969.

45 Macie, T. W., Masek, T. D. and Thordarson, G. G., "A Method for Preventing Ion Thruster Runaway," proposed article for JPL Space Programs Summary.

${ }^{46}$ Marsh, E. L., "The Attitude Control of a Flexible Solar Electric Spacecraft," AIAA Paper 70-1140, AIAA Eighth Electric Propulsion Conference, August 1970. 